\title{
Differential cytotoxic and radiosensitizing effects of silver nanoparticles on triple-negative breast cancer and non-triple-negative breast cells
}

This article was published in the following Dove Press journal:

International Journal of Nanomedicine

II June 2015

Number of times this article has been viewed

\author{
Jessica Swanner ${ }^{\prime}$ \\ Jade Mims $^{2}$ \\ David L Carroll ${ }^{3,4}$ \\ Steven A Akman ${ }^{5}$ \\ Cristina M Furdui ${ }^{2}$ \\ Suzy V Torti ${ }^{6}$ \\ Ravi N Singh ${ }^{1,7}$
}

'Department of Cancer Biology, Wake Forest University Health

Sciences, Winston-Salem, NC, USA; ${ }^{2}$ Department of Internal Medicine, Section on Molecular Medicine, Wake Forest University Health Sciences, Winston-Salem, NC, USA; ${ }^{3}$ Center for Nanoscale and Molecular Materials, Wake Forest University, Winston-Salem, NC, USA; ${ }^{4}$ Department of Physics, Wake Forest University, Winston-Salem, NC, USA;

${ }^{5}$ Roper St Francis Cancer Care, Charleston, SC, USA; ${ }^{6}$ Department of Molecular Biology and Biophysics, University of Connecticut Health Center, CT, USA; ${ }^{7}$ Comprehensive Cancer Center of Wake Forest School of Medicine, Winston-Salem, NC, USA

Correspondence: Ravi N Singh Department of Cancer Biology, Wake Forest University Health Sciences, Hanes Building, Room 4045, Medical Center Boulevard, Winston-Salem, NC 27I57, USA

$\mathrm{Tel}+\mathrm{I} 3367134434$

Fax +I 3367160255

Email rasingh@wakehealth.edu

\begin{abstract}
Identification of differential sensitivity of cancer cells as compared to normal cells has the potential to reveal a therapeutic window for the use of silver nanoparticles (AgNPs) as a therapeutic agent for cancer therapy. Exposure to AgNPs is known to cause dose-dependent toxicities, including induction of oxidative stress and DNA damage, which can lead to cell death. Triple-negative breast cancer (TNBC) subtypes are more vulnerable to agents that cause oxidative stress and DNA damage than are other breast cancer subtypes. We hypothesized that TNBC may be susceptible to AgNP cytotoxicity, a potential vulnerability that could be exploited for the development of new therapeutic agents. We show that AgNPs are highly cytotoxic toward TNBC cells at doses that have little effect on nontumorigenic breast cells or cells derived from liver, kidney, and monocyte lineages. AgNPs induced more DNA and oxidative damage in TNBC cells than in other breast cells. In vitro and in vivo studies showed that AgNPs reduce TNBC growth and improve radiation therapy. These studies show that unmodified AgNPs act as a selftherapeutic agent with a combination of selective cytotoxicity and radiation dose-enhancement effects in TNBC at doses that are nontoxic to noncancerous breast and other cells.
\end{abstract}

Keywords: DNA damage, radiation sensitizer, glutathione, redox

\section{Introduction}

As the tools to produce, characterize, and manipulate materials on the nanometer scale have improved, new opportunities to apply nanotechnology for the diagnosis and treatment of cancer continue to emerge. ${ }^{1-3}$ Among nanomaterials, silver nanoparticles (AgNPs) are the most widely applied for both commercial and clinical biomedical applications. ${ }^{4}$ Preclinical studies on AgNPs show that they possess cytotoxic activity toward a variety of cancer cell lines, including breast, ${ }^{5-7}$ glioblastoma, ${ }^{8-10}$ cervical, ${ }^{11}$ liver, ${ }^{12}$ lung, ${ }^{13}$ and leukemia. ${ }^{14,15}$ The ability of AgNPs to act as radiosensitizers has been observed for the treatment of glioma, ${ }^{10,16}$ gastric cancer, ${ }^{17}$ and breast cancer. ${ }^{18}$ The unique interactions of AgNPs with light may offer additional possibilities for cancer imaging and diagnosis. ${ }^{19}$

Clinical translation of nanomaterials for cancer therapy has been hampered by concerns about the potential toxicity of engineered nanomaterials. However, the unique toxicity profiles of nanoparticles may also offer an opportunity to exploit specific vulnerabilities in cancer, provided that an appropriate disease target could be identified. ${ }^{20,21}$ In this case, the nanomaterial itself would act as the therapeutic agent. Exposure of cells to AgNPs has been reported to cause DNA damage and induce oxidative stress, ${ }^{22,23}$ and cells deficient in their capacity to repair DNA damage are 
more susceptible to AgNP toxicity. ${ }^{23}$ Breast cancer cells may be more sensitive than noncancerous breast cells to agents that induce oxidative stress. ${ }^{24-27}$ Because breast cancer is a heterogeneous disease made up of multiple subtypes ${ }^{28}$ and resistance to established therapies and dose-limiting toxic side effects frequently occur, new therapeutic agents are needed. For the development of novel breast cancer therapeutics, attention must be paid to therapeutic efficacy in specific subtypes of the disease. ${ }^{28}$

Triple-negative breast cancer (TNBC) is an aggressive, heterogeneous subclass of breast cancer typically of basal origin, accounts for $15 \%-20 \%$ of all invasive breast cancers, and is characterized by low expression or lack of expression of estrogen (ER), progesterone (PR), and human epidermal growth factor receptors, ${ }^{29}$ which renders modern targeted therapeutics ineffective. Compared to other types of breast tumors, TNBC presents with a higher histological grade and has a greater likelihood of metastasis, and the 5-year survival rate of women diagnosed with TNBC is markedly decreased. ${ }^{29}$ There is a pressing need for effective therapeutics to treat this form of breast cancer. Due to defects in DNA repair pathways, TNBC may be more vulnerable to DNAdamaging agents than are other forms of breast cancer, ${ }^{30}$ and therefore may also be more susceptible to AgNP treatment. However, little is known about the relative effects of AgNPs or other nanoparticles on different breast cancer subtypes.

Silver possesses a strong affinity for thiol groups, but the role intracellular thiols such as glutathione (GSH) play in AgNPinduced damage remains unclear. GSH, a tripeptide thiol, plays a pivotal role in mitigating damage induced by cancer drugs, radiation, and various other pollutants and toxins. ${ }^{31,32}$ Silver can directly bind thiol antioxidants, ${ }^{33}$ and AgNP exposure can lead to the depletion of GSH. ${ }^{34}$ Increased levels of GSH have been found in malignant cells when compared to nonmalignant cells, and GSH-mediated sulfation is an important resistance mechanism of breast and other carcinomas to chemotherapeutic drugs and radiation therapy. ${ }^{35,36}$ Understanding the role GSH plays in the detoxification of AgNPs may have important implications for future clinical applications of this material.

Based on vulnerabilities to oxidative stress and DNAdamaging agents, ${ }^{30}$ we hypothesized that TNBC would be susceptible to AgNP cytotoxicity, which may offer an opportunity for therapeutic selectivity. Additionally, it is unknown if the radiation-sensitizing effects of AgNPs differ between cancer cells and noncancerous cells. Therefore, we examined the cytotoxicity of AgNPs in a series of cell lines, including TNBC, luminal A breast cancer, and cell lines derived from noncancerous human breast tissue. Because thiol antioxidants contribute to breast cancer resistance to chemo- and radiation therapy, we determined the influence of GSH on the toxicity profile of AgNPs. Finally, we assessed the effects of AgNPs alone or in combination with ionizing radiation (IR) on DNA damage in vitro and determined the anticancer efficacy of these treatments in a mouse model of TNBC.

\section{Materials and methods Silver nanoparticles}

A powder of spherical AgNPs capped with polyvinylpyrrolidone (PVP, $0.2 \mathrm{wt} \%$ ) with a nominal diameter of approximately 20-30 nm (SkySpring Nanomaterials, Inc., Houston, TX, USA) was used for all studies. Nanoparticle dispersions were prepared by hydrating $20 \mathrm{mg}$ of AgNPs with $10 \mathrm{~mL}$ of degassed Milli-Q (type I) water in a $20 \mathrm{~mL}$ glass vial, followed by 30 minutes of bath sonication. Nanoparticle suspensions were rendered isotonic by the addition of one part in 10 of $10 \times$ phosphate-buffered saline (PBS) (Invitrogen, Carlsbad, CA, USA) prior to dilution in cell culture media.

\section{Cell culture}

184B5 cells were obtained from Dr Martha Stampfer of the Lawrence Berkeley National Laboratory and cultured as previously described. ${ }^{37} \mathrm{MCF}-7, \mathrm{MCF}-10 \mathrm{~A}, \mathrm{MDA}-\mathrm{MB}-231$, human mammary epithelial cells (HMEC), BT-549, and SUM-159 cells were purchased from ATCC (American Type Culture Collection) (Manassas, VA, USA). MCF-7 cells were grown in DMEM/F12 supplemented with penicillin, streptomycin, L-glutamine, $10 \mu \mathrm{g} / \mathrm{mL}$ insulin, $10 \mathrm{ng} / \mathrm{mL}$ epidermal growth factor, $0.5 \mu \mathrm{g} / \mathrm{mL}$ hydrocortisone, and $10 \%$ fetal bovine serum (FBS). MCF-10A cells were grown in DMEM/ F12 supplemented with penicillin, streptomycin, $2 \mathrm{mM}$ L-glutamine, $5 \%$ heat inactivated horse serum, $10 \mu \mathrm{g} / \mathrm{mL}$ insulin, $20 \mathrm{ng} / \mathrm{mL}$ epidermal growth factor, $0.5 \mu \mathrm{g} / \mathrm{mL}$ hydrocortisone, and $100 \mathrm{ng} / \mathrm{mL}$ cholera toxin. MDA-MB-231 cells were grown in DMEM supplemented with 10\% FBS (vol:vol), $2 \mathrm{mM}$ L-glutamine, penicillin $(250 \mathrm{U} / \mathrm{mL})$, and streptomycin $(250 \mu \mathrm{g} / \mathrm{mL})$ (all from Invitrogen). HMEC cells were grown in Mammary Epithelium Basal Medium supplemented with $2.0 \mathrm{~mL}$ BPE, 0.5 mL hEGF, $0.5 \mathrm{~mL}$ insulin, $0.5 \mathrm{~mL}$ hydrocortisone, and $0.5 \mathrm{~mL}$ GA-100 (all from Lonza). BT-549 cells were grown in RPMI supplemented with 1\% penicillin and streptomycin, and 10\% FBS. SUM-159 cells were grown in Ham's F12 supplemented with 1\% penicillin and streptomycin, 1\% L-glutamine, 5\% FBS, $5 \mu \mathrm{g} / \mathrm{mL}$ insulin, $1 \mu \mathrm{g} / \mathrm{mL}$ hydrocortisone, and $10 \mu \mathrm{M}$ HEPES. Cells were grown in tissue culture-treated plastics purchased from Corning Life Sciences (Lowell, MA, USA). 


\section{Dynamic light scattering}

Hydrodynamic diameter and zeta potential were measured using the Zetasizer Nano ZS90 (Malvern Instruments, Malvern, UK) at $25^{\circ} \mathrm{C}$, with automatic settings, adjusting for the refractive index of the dispersant. The particles were diluted to $40 \mu \mathrm{g} / \mathrm{mL}$, and $1 \mathrm{~mL}$ was added to a disposable, clear plastic cuvette (Sarstedt, Newton, NC, USA). Each measurement was taken in triplicate.

\section{Nanoparticle tracking analysis}

Measurements were made using the Nanosight NS500 (Malvern Instruments) at $25^{\circ} \mathrm{C}$. AgNP dispersions $(2 \mathrm{mg} / \mathrm{mL})$ were diluted 1:5,000 in degassed Milli-Q (type I) water. The following settings were used for triplicate measurements of five preparations: NTA (nanoparticles tracking analysis) software version 2.3; camera shutter: 32 milliseconds; duration: 90; threshold: 6 .

\section{Electron microscopy}

Six hundred thousand cells per well were plated in $3 \mathrm{~mL}$ of media and allowed to recover for 24 hours at $37^{\circ} \mathrm{C}$. Two wells on a six-well plate were used for each cell line. One well of each cell line was treated with a $25 \mu \mathrm{g} / \mathrm{mL} \mathrm{AgNP}$ dilution for 24 hours at $37^{\circ} \mathrm{C}$, while the other well was used as a control. Cells were washed twice with PBS, fresh media was added, and then allowed to incubate for 30 minutes. Cells were trypsinized, pelleted, washed three times with PBS, resuspended in glutaraldehyde, and incubated at $4^{\circ} \mathrm{C}$ overnight. Cells were embedded in resin, cut into ultrathin sections $(80 \mathrm{~nm})$, placed on copper-coated Formvar ${ }^{\circledR}$ grids, and imaged using a Tecnai ${ }^{\mathrm{TM}}$ Spirit transmission electron microscope (FEI, Hillsboro, OR, USA).

\section{MTT assay}

Cells were grown to $\log$ phase in their respective media, trypsinized, washed in PBS, and plated on 96-well plates at a density of 6,000 cells per well in $200 \mu \mathrm{L}$ of complete media. Cells were allowed to recover for 18 hours and were then exposed to AgNPs for 24 hours. Media containing AgNPs were replaced with $200 \mu \mathrm{L}$ of media containing $0.5 \mathrm{mg} / \mathrm{mL}$ MTT and incubated for 1 hour at $37^{\circ} \mathrm{C}$. Media were removed, and cells were lysed in $200 \mu \mathrm{L}$ of DMSO and read using a Molecular Devices Emax Precision Microplate Reader at $595 \mathrm{~nm}$ and corrected for background at $650 \mathrm{~nm}$. For GSH supplementation or depletion studies, 18 hours after plating the cells in 96-well dishes, the media were replaced with fresh complete media, complete media containing GSH, or complete media with buthionine sulfoximine (BSO) (Sigma-Aldrich,
St Louis, MO, USA). Cells were incubated overnight, and then the media were replaced with $200 \mu \mathrm{L}$ of fresh complete media containing increasing concentrations of AgNPs, and the viability was assessed as aforementioned.

\section{BrdU assay}

Cells were grown, plated, and exposed to AgNPs as described for MTT assays. The toxicity of the AgNPs was then evaluated using a commercial BrdU ELISA (enzyme-linked immunosorbent assay) kit (EMD Millipore, Billerica, MA, USA), according to the manufacturer's instructions. BrdU incorporation was quantified by measuring absorbance at $450 \mathrm{~nm}$ (correcting for background at $595 \mathrm{~nm}$ ) using a Molecular Devices Emax Precision Microplate Reader.

\section{Clonogenic assay}

Cells were grown to log phase in their respective media, trypsinized, washed in PBS, and plated on six-well plates at a density of 300 cells per well and were allowed to adhere for 18 hours. Increasing concentrations of AgNPs $(0-100 \mu \mathrm{g} / \mathrm{mL})$ were added to each well and incubated for 24 hours at $37^{\circ} \mathrm{C}$. For each condition, three wells were used. Cells were incubated with AgNPs with or without GSH or BSO for 24 hours, and then culture media were removed. The cells were washed with PBS, and fresh media were added and replaced every 2-3 days. Fourteen days after plating, the cells were washed and fixed with methanol, glacial acetic acid, and water (1:1:8 [vol:vol:vol]), then stained with crystal violet. Colonies of at least 50 cells were counted by hand. All data are expressed as plating efficiency relative to the relevant control in the absence of AgNPs.

\section{Quantification of sulfenic acids}

Cells were plated in $10 \mathrm{~cm}$ dishes at a density of $3 \times 10^{6}$ per plate and were allowed to adhere for 18 hours. Cells were treated with 10 or $25 \mu \mathrm{g} / \mathrm{mL}$ AgNPs for 24 hours at $37^{\circ} \mathrm{C}$. The cells were lysed in $0.3 \mathrm{~mL}$ Triton lysis buffer $(20 \mathrm{mM}$ Tris-HCl; 5 mM EDTA; 1\% Triton X-100; 1\% Halt protease and phosphatase inhibitor cocktail [100×]; $\mathrm{pH} 8.3$ ) supplemented with $200 \mathrm{U} / \mathrm{mL}$ catalase and $1 \mathrm{mM}$ biotin1,3-cyclopentanedione. The lysates were incubated for 45 minutes, iodoacetamide or N-ethylmaleimide were added to block thiols, followed by centrifugation at $10,000 \times g$ for 10 minutes. The lysates were normalized for their protein concentration across different treatment conditions and analyzed by Western blot using antibiotin, HRP-linked antibody (Cell Signaling Technology, Danvers, MA, USA). The Western blots were developed using Western Lightning ${ }^{\mathrm{TM}}$ 
Plus-ECL reagents followed by exposure to autoradiography film (Blue Ultra autorad film from GeneMate; BioExpress, Kaysville, UT, USA).

\section{lonizing radiation treatment in vitro}

Cells were plated as described earlier for clonogenic assays. Cells were incubated with AgNPs for 24 hours, then were washed with PBS, and fresh media was added. IR at doses of 0-4 Gy was administered using an orthovoltage X-ray source at a voltage of $300 \mathrm{kV}$, a current of $10 \mathrm{~mA}$, and a dose rate of $2.39 \mathrm{~Gy} / \mathrm{min}$. Fresh culture media were added every 2-3 days. Fourteen days after plating, the cells were washed, fixed with methanol, glacial acetic acid, and water (1:1:8 [vol:vol:vol]), then stained with crystal violet. All data are expressed relative to the number of colonies counted for each treatment condition in the absence of AgNPs.

\section{Quantification of $\gamma \mathrm{H} 2 \mathrm{AX}$}

Around 15,000 cells per well on eight 96-well black plates were plated in $200 \mu \mathrm{L}$ of media and allowed to recover for 24 hours at $37^{\circ} \mathrm{C}$. AgNPs were added to four wells per condition and incubated for 24 hours at $37^{\circ} \mathrm{C}$. Cell plates were irradiated using an orthovoltage X-ray source with the parameters listed earlier. Quantification of $\gamma \mathrm{H} 2 \mathrm{AX}$ was performed using a commercially available ELISA kit (Quantikine, R\&D Systems, Minneapolis, MN, USA), according to the manufacturer's instructions. Plates were fixed and stored at $4^{\circ} \mathrm{C}$ in the fixing solution overnight, and then $\gamma \mathrm{H} 2 \mathrm{AX}$ labeling was performed and was quantified using a Molecular Devices Emax Precision Microplate Reader at an excitation of $540 \mathrm{~nm}$ and an emission of $600 \mathrm{~nm}$.

\section{Animal handling}

All animal studies were performed with prior approval from the Institutional Animal Care and Use Committee of Wake Forest University Health Sciences. Female nu/nu athymic mice from Charles River Laboratories (5-8 weeks old) were housed five per cage in standard plastic cages, provided food and water ad libitum, and maintained on a 12-hour light/ dark cycle.

\section{In vivo tumor regression study}

MDA-MB-231 cells were and harvested as described, then resuspended in a 1:1 mixture of ice cold PBS and Matrigel (BD Biosciences, San Jose, CA, USA) at a concentration of $2 \times 10^{7}$ cells $/ \mathrm{mL}$. Around $100 \mu \mathrm{L}\left(2 \times 10^{6}\right.$ cells $)$ of the suspension was injected into the right hind flanks of the mice.
Tumor growth was monitored by calipers, and the volume was determined using the formula: volume $=0.52 \times($ width $) \times$ (length) $\times($ width + length $) / 2$, where length and width are the two largest perpendicular diameters. When the tumors reached an average volume of $111 \mathrm{~mm}^{3}$ (approximately 2 weeks postimplant), mice were randomly divided into four groups of five to eight mice. Control mice received no treatment; the second group received an intratumoral injection of $0.2 \mu \mathrm{g} \mathrm{AgNPs} / 1 \mathrm{~mm}^{3}$ tumor volume; the third group received IR (4 Gy) using an orthovoltage X-ray source at a voltage of $300 \mathrm{kV}$, a current of $10 \mathrm{~mA}$, and a dose rate of $2.39 \mathrm{~Gy} / \mathrm{min}$ (assuming a flat dose distribution due to the small tumor size); and the final group of mice received a combination therapeutic regimen of intratumoral AgNPs followed by IR (4 Gy) 48 hours later. Three weeks later, each treatment was repeated. The tumor was extended away from the body, and mice receiving radiation were shielded by lead, excluding the tumor, to minimize irradiation to other parts of the body.

\section{Statistical analysis}

Data were analyzed using SigmaPlot software (version 12.0; Systat Software Inc, San Jose, CA, USA). Unless otherwise noted, all the data are reported as the sample mean \pm standard deviation (SD). Data series in Figures 2 and 4-8 were analyzed by two-way ANOVA and Student's $t$-tests for subsequent post hoc pairwise comparisons. Data in Figure 7 were found to best fit a second-order polynomial regression model.

\section{Results}

\section{Physicochemical characterization of silver nanoparticles}

Initially, we determined the physicochemical characteristics of the AgNPs used for this study. A desiccated silver nanopowder made from AgNPs stabilized with PVP was selected due to the long shelf life of AgNPs in this form and the potential for development of similar AgNP formulations for generation of "on demand" suspensions, an asset for future drug development. ${ }^{38}$ Prior to use, AgNPs in the nanopowder were dispersed in deionized water at a concentration of $2 \mathrm{mg} / \mathrm{mL}$ and characterized for size, shape, dispersion stability, zeta potential, and optical absorbance by transmission electron microscopy (TEM), dynamic light scattering (DLS), NTA, and ultraviolet/visible light (UV/Vis) spectroscopy, respectively. A minimum of five separate dispersions were used for each analysis to ensure reproducibility of the measured 
A

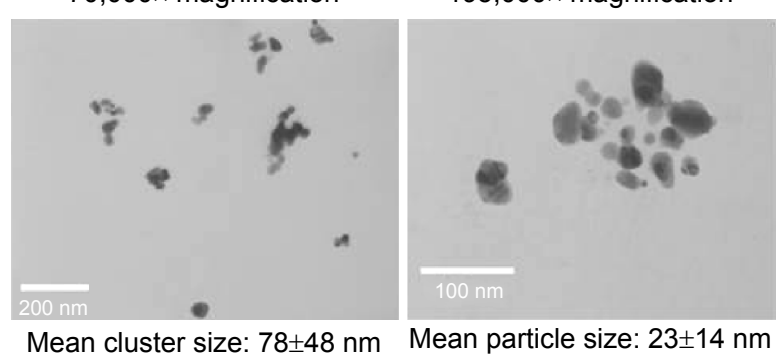

B

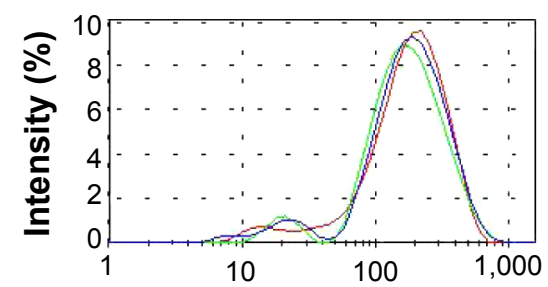

Hydrodynamic diameter $(\mathrm{nm})$
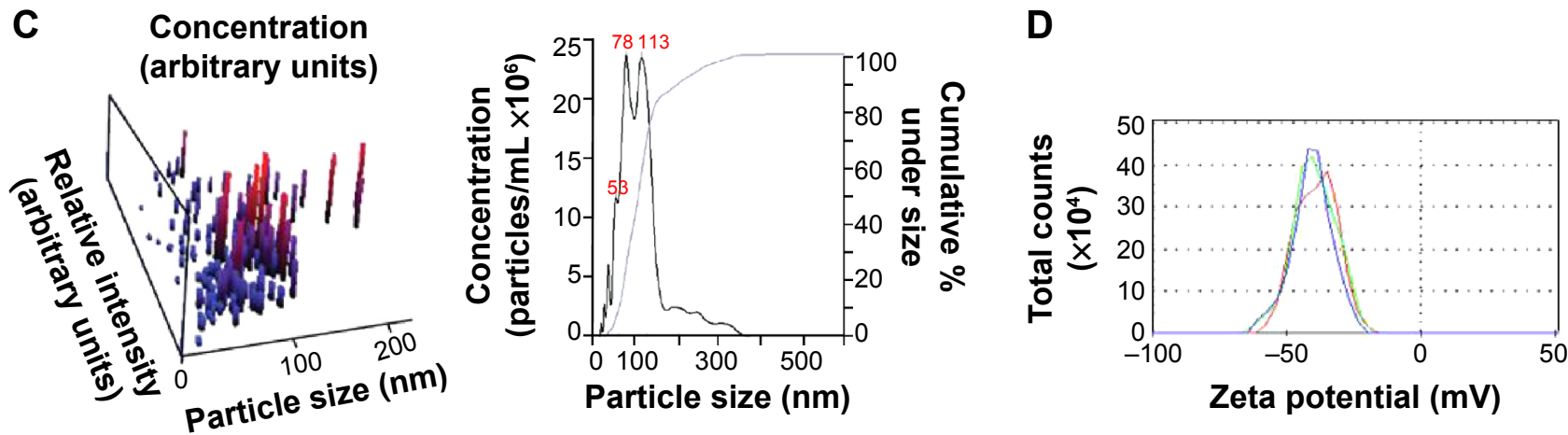

Figure I Physicochemical characterization of AgNPs.

Notes: (A) Average cluster and particle size analyzed via TEM. (B) Hydrodynamic diameter of AgNPs (triplicate measurements) analyzed via DLS. (C) Hydrodynamic diameter of individual AgNPs analyzed by NTA. (D) Zeta potential of AgNPs analyzed via DLS (triplicate measurements).

Abbreviations: AgNPs, silver nanoparticles; TEM, transmission electron microscopy; DLS, dynamic light scattering; NTA, nanoparticle tracking analysis.

physicochemical characteristics. Representative data from a single dispersion of AgNPs are shown in Figure 1, and data summarizing all of the samples are shown in Table 1. Characterization of the particles by TEM indicated that they were generally spherical (Figure 1A). The size of the individual, dehydrated AgNPs was $23 \pm 14 \mathrm{~nm}$, though many appeared to be in clusters of 3-4 particles even after sonication (average cluster size of $78 \pm 48 \mathrm{~nm}$ [Figure 1A]). Similarly, DLS analysis of the hydrated particle suspension indicated a bimodal particle size distribution with peaks near 20 and $225 \mathrm{~nm}$ (average hydrodynamic diameter of $131 \pm 17 \mathrm{~nm}$ ), confirming that the nanoparticles were present as both individual particles and as small aggregates in the dispersion (Figure 1B).

DLS acquires data by detecting a "speckle" pattern of constructive and destructive interference of light scattered off of billions or more particles. Brownian movement of the particles will change the phase overlap of the scattered light causing the "speckle" pattern to fluctuate in intensity. The rate of change over time of the "speckle" pattern correlates with the particle velocities. The Stokes-Einstein equation can then be used to relate velocity to a hydrodynamic radius. While DLS provides a powerful statistical analysis of the overall colloidal characteristics of particle dispersion, it does not provide information on individual particles in the dispersion. An analysis of individual, hydrated particle size and particle concentration can be obtained using NTA. However, NTA loses the statistical power of DLS since less than 1,000 particles typically are characterized by NTA. In contrast to DLS, NTA directly tracks the Brownian movement of individual particles using a charge-coupled device camera to detect light scattered off of particles. A diffusion velocity can then be determined for each particle. Like DLS,

Table I Physicochemical characterization of silver nanoparticle dispersions

\begin{tabular}{llll}
\hline & DLS & NTA & UV/Vis \\
\hline Hydrodynamic diameter $(\mathrm{nm})$ & $131 \pm 17$ & $113.5 \pm 13$ & NA \\
Polydispersity index & $0.46 \pm 0.04$ & NA & NA \\
Zeta potential $(\mathrm{mV})$ & $-35.9 \pm 7.8$ & $\mathrm{NA}$ & NA \\
$<150 \mathrm{~nm}(\%)$ & $\mathrm{NA}$ & $74 \pm 10$ & NA \\
$<300 \mathrm{~nm}(\%)$ & $\mathrm{NA}$ & $98 \pm 0.6$ & NA \\
$<370 \mathrm{~nm}(\%)$ & $\mathrm{NA}$ & 100 & NA \\
Concentration (particles $/ \mathrm{mL})$ & NA & $3.3 \pm \mathrm{I} .1 \times 10^{11}$ & NA \\
Peak absorbance $(\mathrm{nm})$ & NA & NA & $4 \mathrm{II}$ \\
\hline
\end{tabular}

Note: Data is presented as mean $\pm S D$, unless otherwise specified.

Abbreviations: DLS, dynamic light scattering; NTA, nanoparticle tracking analysis; UV/Vis, ultraviolet/visible light. 
the Stokes-Einstein equation is also used to determine a hydrodynamic diameter. Size analysis by NTA was consistent with DLS and indicated that the majority (approximately $74 \%$ ) of particles or particle clusters possessed a hydrodynamic diameter between 30 and $150 \mathrm{~nm}$, with an average of $113.5 \pm 13 \mathrm{~nm}$ (Figure 1C). The zeta potential of AgNPs in water at $\mathrm{pH} 7$ was approximately $-36 \mathrm{mV}$, indicating good colloidal stability. UV/Vis is absorbance measurements show that the smaller-sized particles (separated by centrifugation to sediment larger clusters) exhibited a plasmon resonance at $411 \mathrm{~nm}$, which is in the expected range for spherical AgNPs less than $50 \mathrm{~nm}$ in diameter. As shown in Table 1, the overall characteristics for the particle dispersions were highly reproducible despite the heterogeneity of particle size due to the presence of AgNPs aggregates. Particle dispersions were used within 1 month of preparation and were characterized again immediately prior to use. In agreement with previous studies, ${ }^{39}$ aqueous dispersions of AgNPs showed no significant changes in particle properties including size, shape, zeta potential, and absorbance characteristics when stored at $2 \mathrm{mg} / \mathrm{mL}$ in degassed, type I (Milli-Q) water at room temperature in the dark for up to 1 month.

\section{Silver nanoparticles are cytotoxic to TNBC cells at doses that are noncytotoxic to nontumorigenic breast cells}

Exposure to AgNPs causes dose-dependent toxicities including oxidative stress and DNA damage leading to cell death in several mammalian cell lines. ${ }^{23,40}$ Although the anticancer activity of AgNPs has been evaluated in several breast cancer cell lines in vitro ${ }^{5,6}$ and in vivo, ${ }^{7}$ differential effects of AgNPs in TNBC cells as compared to nontumorigenic breast cells have not been shown. Therefore, we evaluated the cytotoxicity of AgNPs in a panel of TNBC cell lines (MDA-MB-231, BT-549, and SUM-159), all of which exhibit features of claudin-low breast cancer, ${ }^{41}$ in ER/PR positive, luminal A-like breast cancer cells (MCF-7), in noncancerous, transformed breast cells (MCF-10A), immortalized HMECs (184B5), ${ }^{42}$ and in poststasis HMECs. ${ }^{43}$

The cytotoxicity of AgNPs initially was evaluated by MTT assay following overnight exposure of cells to increasing concentrations of AgNPs (Figure 2A). Depending on AgNP dose, all three TNBC cell lines were 5- to 10-fold more sensitive to AgNP exposure than the nontumorigenic breast cells. MCF-7 cells were also more sensitive to AgNP exposure than the nontumorigenic breast cells, but were less sensitive than the TNBC cell lines. In Figure 2A, AgNPs were significantly more cytotoxic toward all three TNBC cell lines as compared to all three nontumorigenic breast cell lines at a concentration of $10 \mu \mathrm{g} / \mathrm{mL}$ or greater $(P<0.001)$ or $\mathrm{MCF}-7$ cells at a concentration of $25 \mu \mathrm{g} / \mathrm{mL}$ or greater.

We next assessed the cytotoxicity of AgNPs on a subset of cell lines by clonogenic assay (Figure 2B), which indicates the long-term proliferative capacity of a single cell and allows a longer period of time to track the response of cells after nanoparticle exposure (10-14 days in this study). Once again, TNBC cells were far more sensitive to AgNP treatment. An AgNP dose of $10 \mu \mathrm{g} / \mathrm{mL}$ or greater proved acutely lethal (100\% inhibition of clonogenic growth) to TNBC cells but had far less effect on MCF-10A cells $(<20 \%$ inhibition of clonogenic growth). Additionally, MCF-7 cells were more sensitive to AgNPs than were the noncancerous breast cells, but they were less sensitive than TNBC cells to AgNP exposure. Statistical analysis of differences in clonogenic growth shown in Figure 2B indicated that AgNPs were significantly more cytotoxic toward all three TNBC cell lines as compared to $\mathrm{MCF}-10 \mathrm{~A}$ cells at a concentration equal to or greater than $2.5 \mu \mathrm{g} / \mathrm{mL}(P<0.001)$ or vs MCF-7 at a concentration equal to or greater than $5 \mu \mathrm{g} / \mathrm{mL}(P<0.05)$. Because the cells were exposed to AgNPs overnight and then thoroughly washed to remove any extracellular AgNPs, these long-term effects on self-renewal were observed without a need for continuous culturing in the presence of excess AgNPs.

Following systemic administration, clearance of nanoparticles from the blood may lead to long retention times of AgNPs, and therefore, significant concerns with regard to off-target and chronic toxicities remain. As a step toward addressing these concerns, we determined the impact of AgNPs on TNBC, MCF-7, and noncancerous breast cancer cell lines in direct comparison to MCF-10A cells derived from tissues representative of likely clearance or scavenging routes of AgNPs following systemic administration, including the kidney (HEK293), liver (HEPG2), and monocyte/ macrophage (activated THP-1) cell lines, using the BrdU assay to quantify DNA replication as an indication of cell proliferation. As shown in Figure 2C, AgNPs once again were highly cytotoxic toward TNBC cells and were somewhat less effective in the treatment of MCF-7 cells. All other cell lines were less sensitive to AgNP exposure, indicating that a dosing window may exist in which AgNPs are cytotoxic to TNBC cells without causing substantial damage to non-TNBC cells. Statistical analysis of differences in BrdU incorporation shown in Figure $1 \mathrm{C}$ indicated that AgNPs were significantly more cytotoxic toward all three TNBC cell lines as compared to MCF-10A, 184B5, and HEK293 cells at a concentration equal to or greater than $50 \mu \mathrm{g} / \mathrm{mL}(P<0.05)$ or 
A

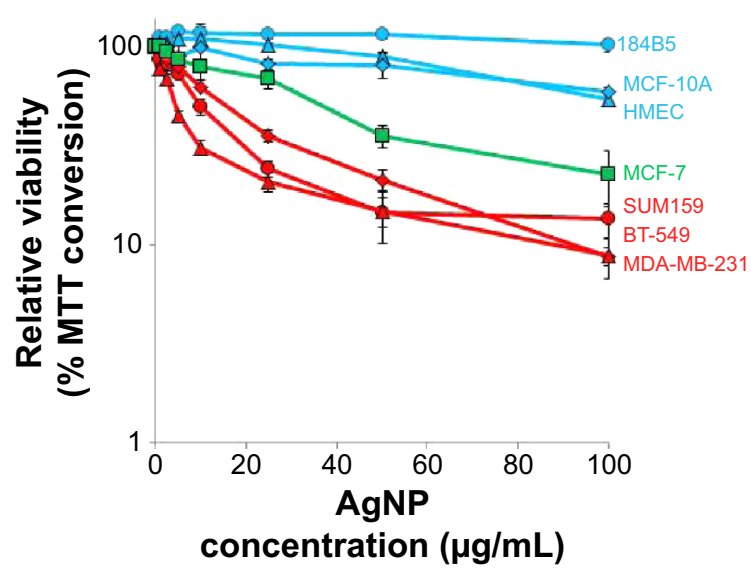

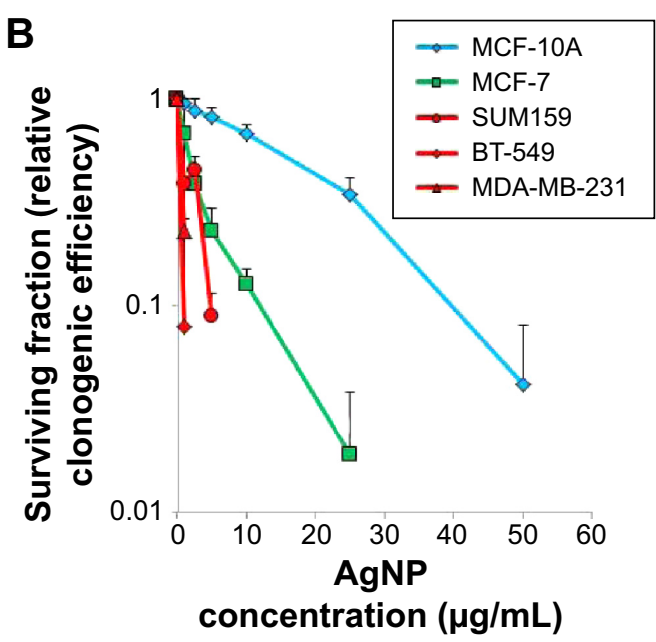

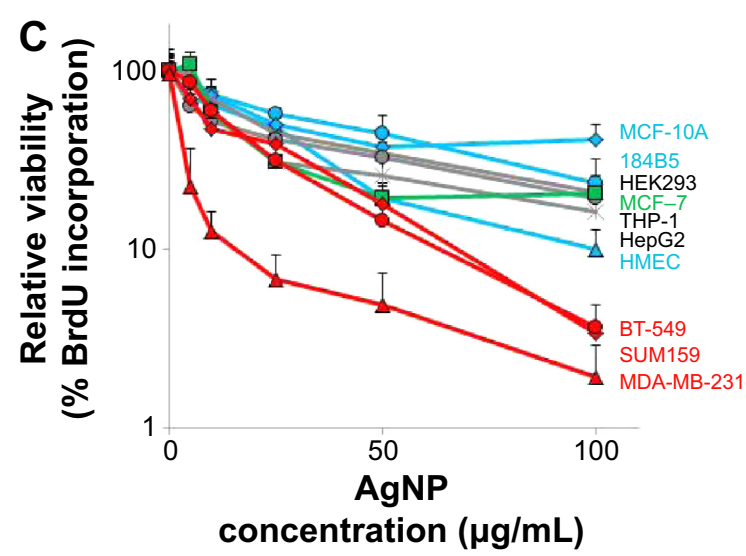

Figure 2 Cytotoxicity of AgNPs toward TNBC and non-TNBC cell lines.

Notes: (A-C) Relative viability of cells after 24 hours treatment with AgNPs (0-100 $\mu \mathrm{g} / \mathrm{mL})$ normalized to untreated control. (A) Nontumorigenic breast cells, TNBC cells, and MCF-7 cells were treated with AgNPs and viability was assessed via MTT assay. (B) Long-term proliferative potential was assessed via clonogenic assay in a subset of breast cell lines. (C) DNA replication was assessed via BrdU incorporation for a subset of breast cell lines and cells derived from the liver, kidney, and monocyte lineages. Data are presented as the mean of triplicate samples \pm SD and are normalized to control cells receiving no AgNPs.

Abbreviations: AgNP, silver nanoparticle; TNBC, triple-negative breast cancer; SD, standard deviation.

vs all non-TNBC cell lines at a concentration of $100 \mu \mathrm{g} / \mathrm{mL}$ $(P<0.05)$.

\section{Uptake of intact silver nanoparticles is necessary for cytotoxicity in TNBC cells} We confirmed by TEM that AgNPs were taken up intact by MDA-MB-231, MCF-7, and MCF-10A cells (Figure 3). No notable differences between cell lines in the number of cells taking up AgNPs were noted. Following internalization, AgNPs were largely confined to endocytic vesicles in all three cell lines. It is possible that $\mathrm{Ag}^{+}$ions could be released during processing or storage of the nanoparticles without substantially changing the physicochemical characteristics of the particles. However, the release of $\mathrm{Ag}^{+}$ions could influence the cytotoxicity profile of AgNPs. Therefore, AgNPs were stored in water for 2 months, and $\mathrm{Ag}^{+}$ions were separated from the intact nanoparticles by filtration through a centrifugal size exclusion column. Dilutions of each fraction were prepared based on the initial concentration of AgNPs added to the column, and then MDA-MB-231 cells were treated with increasing doses of each fraction to assess cytotoxicity. The results of this study demonstrate that the cytotoxicity was dependent on exposure of cells to intact AgNPs and not due to $\mathrm{Ag}^{+}$ions or other substances released during processing or storage of the nanoparticles (Figure 4A). In a separate experiment, cells were treated with cytochalasin $\mathrm{D}$, which will inhibit most forms of endocytosis, prior to adding AgNPs to MDA-MB-231 cells. Inhibition of endocytosis using cytochalasin D antagonized AgNP cytotoxicity indicating that AgNP internalization was needed (Figure 4B). From these experiments, we conclude that the uptake of intact AgNPs is necessary for the cytotoxic effects and that $\mathrm{Ag}^{+}$ions released during preparation or storage play little role in the cytotoxicity profile of the AgNPs used in these studies. 

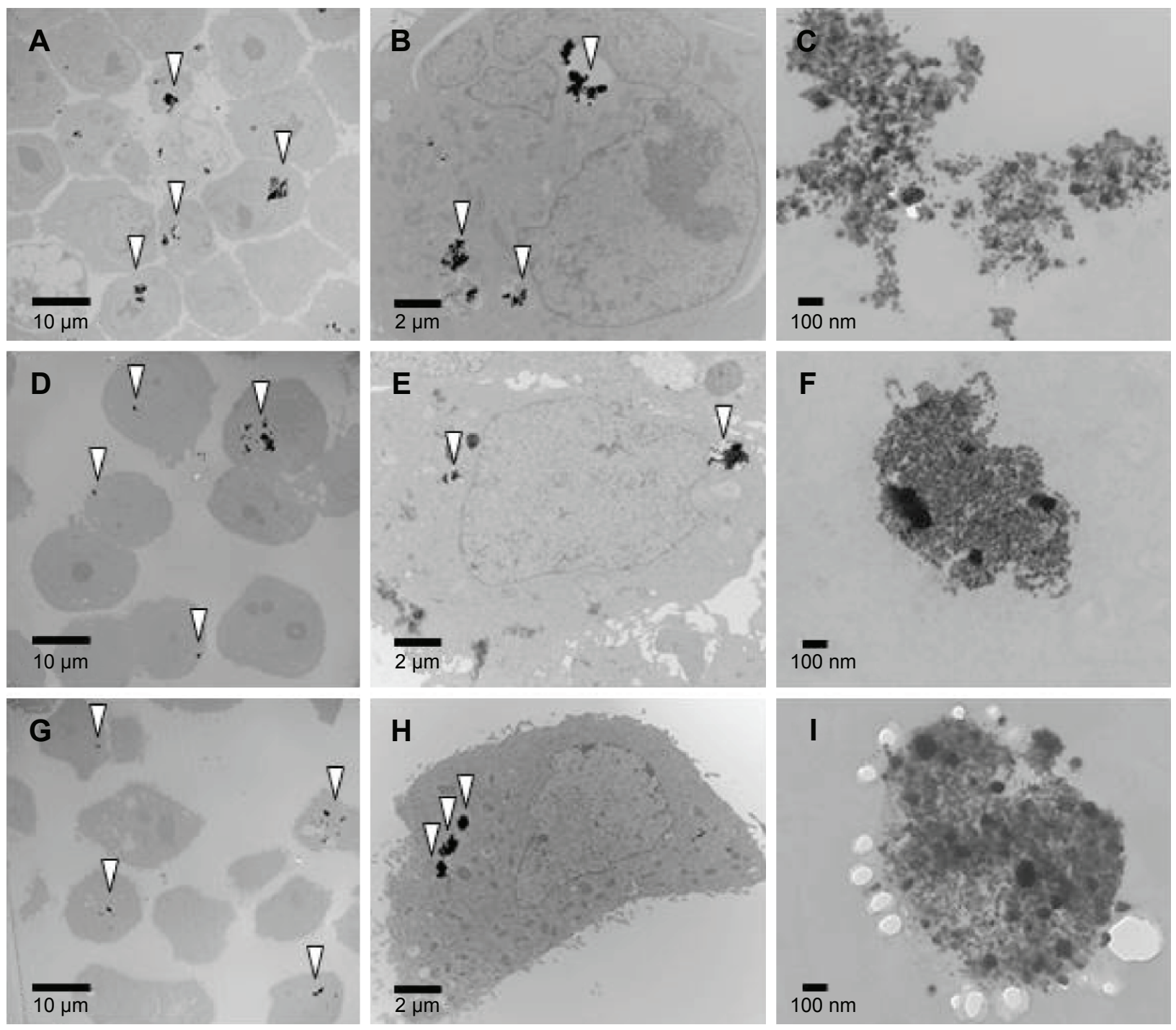

Figure 3 Uptake of AgNPs visualized by TEM.

Notes: MDA-MB-23I (A-C), MCF-7 (D-F), or MCF-IOA (G-I) cells were incubated for 24 hours with AgNPs $(25 \mu \mathrm{g} / \mathrm{mL})$. Ultrathin sections of cells were prepared and imaged by TEM. (A, D, G) TEM images taken at I,200× magnification showing AgNPs taken up by all the three cell lines (white arrowheads); (B, E, H) TEM images taken at 4,800× magnification showing that AgNPs primarily localized to vesicles within cells following uptake (white arrowheads indicate AgNPs); (C, F, I) TEM images taken at 49,000 $\times$ magnification showing intact AgNPs in cell vesicles.

Abbreviations: AgNP, silver nanoparticle; TEM, transmission electron microscopy.

\section{Silver nanoparticles oxidize cysteine thiols in TNBC cells to a greater extent than in non-TNBC and noncancerous breast cells}

Regulation of thiol oxidation is an essential posttranslational process in normal physiology, and thiols can be easily oxidized to sulfenic acid ( $\mathrm{SOH}$ ) and other species under oxidative stress conditions. ${ }^{44}$ Quantification of protein- $\mathrm{SOH}$ in cells provides a sensitive means to measure oxidative damage. To assess the potential for AgNP exposure to generate protein-SOH, we incubated MDA-MB-231, MCF-7, or MCF$10 \mathrm{~A}$ cells with AgNPs at 10 or $25 \mu \mathrm{g} / \mathrm{mL}$ then probed for protein-SOH using a biotin-1,3-cyclopentanedione probe as previously described. ${ }^{45}$ This probe allows for selective detection of this oxidative modification under the cellular conditions in which $\mathrm{SOH}$ are generated. As shown in Figure 5A, exposure of MCF-7 cells to AgNPs causes dose-dependent increases in protein- $\mathrm{SOH}$, though to a lesser degree than in MDA-MB-231 cells. Little change in protein-SOH or cell death is observed in MCF-10A cells following exposure to $\mathrm{AgNPs}$. In contrast, significantly more protein-SOH is generated in MDA-MB-231 cells than in MCF-7 or MCF-10A cells following exposure to $10 \mu \mathrm{g} / \mathrm{mL}$ of AgNPs. At the $25 \mu \mathrm{g} / \mathrm{mL}$ dose, protein-SOH in MDA-MB-231 cells appears to be reduced compared to the $10 \mu \mathrm{g} / \mathrm{mL}$ dose. This dose caused approximately a 10 -fold decrease in cell viability, as shown 
A

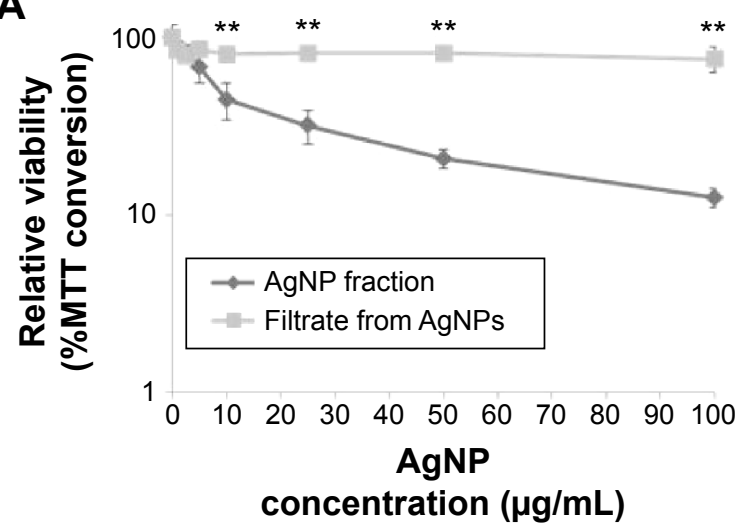

B

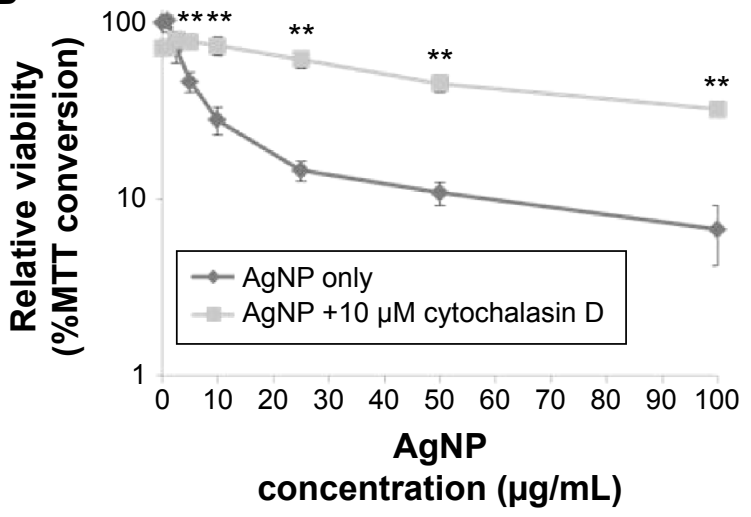

Figure 4 Cytotoxic effects of AgNPs are dependent on uptake and internalization of intact AgNPs.

Notes: (A) Intact AgNPs were separated from any $\mathrm{Ag}^{+}$ions that may have been released during storage using a 3,000 MWCO size exclusion column. MDA-MB-23I cells were treated with dilutions of AgNPs $(0-100 \mu g / \mathrm{mL})$ or equivalently diluted filtrate prepared from the AgNP stock solution, and 24 hours later, cell viability was assessed by MTT assay. (B) MDA-MB-23I cells were treated with AgNPs $(0-100 \mu \mathrm{g} / \mathrm{mL})$ for 24 hours with and without a $10 \mu M$ treatment of the endocytosis inhibitor, cytochalasin $\mathrm{D}$, and viability was assessed via MTT conversion. Data are presented as the mean of triplicate samples \pm SD. Statistically significant differences between comparisons are indicated by $* * P<0.01$.

Abbreviations: AgNP, silver nanoparticle; MWCO, molecular weight cut-off; SD, standard deviation.

A

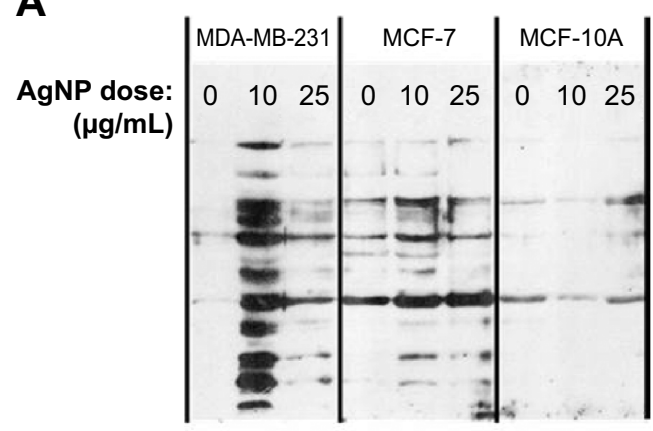

B-actin

C

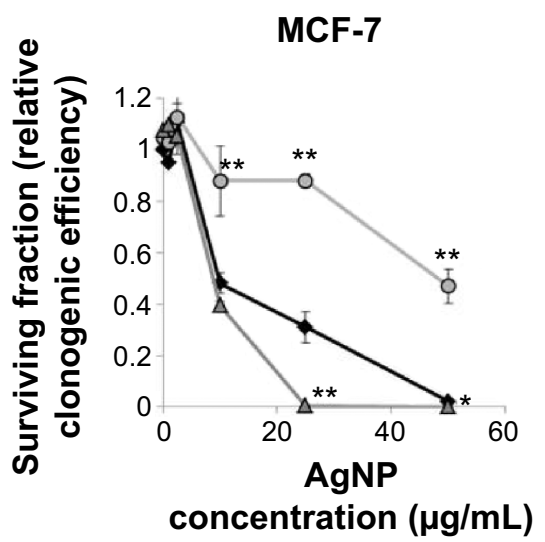

B

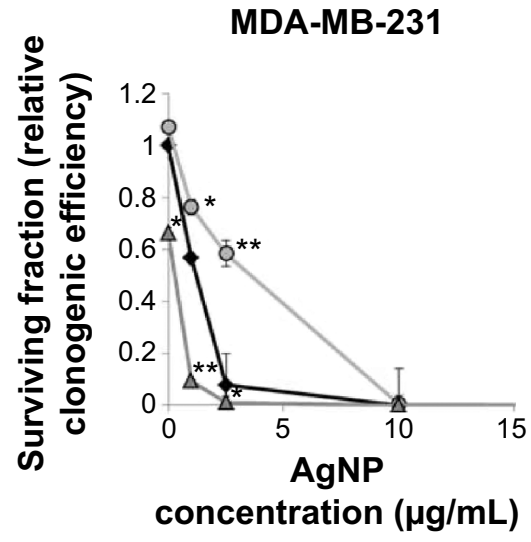

D

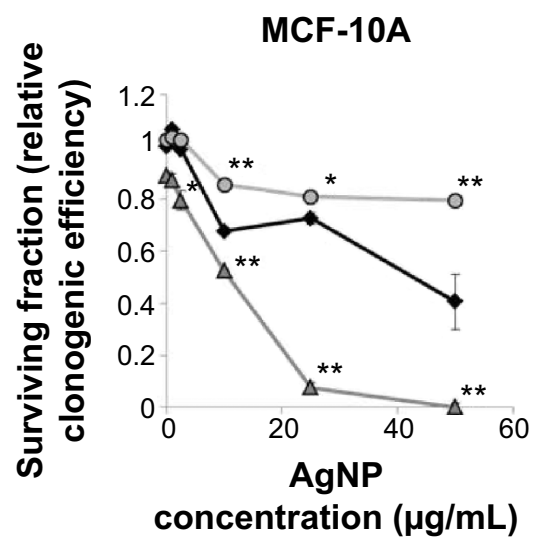

$\rightarrow$ Complete media $\rightarrow 10 \mathrm{mM} \mathrm{GSH} \quad \longleftarrow 50 \mu \mathrm{M} \mathrm{BSO}$

Figure 5 Quantification of protein SOHs following AgNP exposure and determination of influence of glutathione level on AgNP cytotoxicity.

Notes: (A) Generation of protein sulfenic acids was assessed by Western blot in MDA-MB-23I, MCF-7, and MCF-10A cells following overnight exposure to AgNPs at 0, 10, or $25 \mu \mathrm{g} / \mathrm{mL}$. (B-D) MDA-MB-23I, MCF-7, and MCF-10A were incubated overnight in media supplemented with $10 \mathrm{mM}$ GSH or $50 \mu \mathrm{M}$ BSO. The following day, fresh media containing increasing concentrations of $\mathrm{AgNPs}(0-50 \mu \mathrm{g} / \mathrm{mL})$ was added. After overnight incubation, cells were thoroughly washed, then provided fresh media. About 10-14 days later, plates were stained with crystal violet and colonies were counted to determine clonogenic growth. (B) TNBC cells (MDA-MB-23। cells), (C) luminal A breast cells (MCF-7), and (D) nontumorigenic breast cells (MCF-IOA). Data are presented as the mean of six independent samples \pm SD and are normalized to the untreated control receiving no AgNPs. Statistically significant differences in clonogenic growth $(P<0.05)$ in pairwise comparisons between cells treated with AgNPs and GSH or BSO and cells treated with and equivalent dose of AgNPs alone are indicated by the $* P<0.05$ or $* * P<0.01$.

Abbreviations: AgNP, silver nanoparticle; GSH, glutathione; TNBC, triple-negative breast cancer; BSO, buthionine sulfoximine; SD, standard deviation; SOH, sulfenic acid. 
in Figure 2A, and therefore, increased cell death may have contributed to the reduced level of protein-SOH detected for MDA-MB-231 cells treated with $25 \mu \mathrm{g} / \mathrm{mL}$ of AgNPs. Increased cell death in MDA-MB-231 cells following AgNP exposure was confirmed by a flow cytometry cell death assay based on labeling dead cells with a fluorescent dye (dead cell discriminator) that is not taken up by live cells (Figure S1). AgNPs caused 3-fold more cell death in MDA-MB-231 cells as compared to MCF-7 cells at both the $10 \mu \mathrm{g} / \mathrm{mL}$ dose (11.76\% vs $4.86 \%$ cell death, respectively) and the $25 \mu \mathrm{g} /$ $\mathrm{mL}$ dose $(21.63 \%$ vs $7.65 \%$ cell death). In comparison, less than $1 \%$ of MCF-10A cells were dead at either dose of AgNPs. These results indicate that the oxidative modification of cysteine thiols induced by AgNPs in the triple-negative MDA-MB-231 cell line is far greater than in MCF-7 or MCF$10 \mathrm{~A}$ cells, which is consistent with the cytotoxicity profile of AgNPs in these three cell lines.

Glutathione and enzymes of the GSH metabolic pathway play a significant part in redox-regulated cell signaling and in the development of chemotherapy and radiation resistance. ${ }^{36}$ Development of a basic understanding of the role GSH plays in the relative cytotoxicity and detoxification of AgNPs may be important for the identification of possible resistance mechanisms to AgNP-based cancer therapy. Conversely, depletion of GSH can sensitize cancer cells including breast cancer to therapy. ${ }^{32}$ Therefore, we investigated the role GSH levels play in determining cell sensitivity to AgNPs using the clonogenic assay. Cells were pretreated with $10 \mathrm{mM}$ GSH or $50 \mu \mathrm{M}$ BSO, a selective GSH synthesis inhibitor, overnight and then the culture media was replaced with normal media prior to AgNP exposure. The toxicity of AgNPs was significantly reduced in MDA-MB-231, MCF-7, and MCF-10A cells following pretreatment with GSH (Figure 5B-D). However, at AgNP treatment doses of $10 \mu \mathrm{g} / \mathrm{mL}$ or greater, exogenous GSH did not protect MDAMB-231 cells, but continued to offer substantial protection for MCF-7 and MCF-10A cells. Selective depletion of GSH by BSO resulted in increased AgNP toxicity in all cell lines. Because of the high cytotoxicity of AgNPs alone in MDAMB-231 cells, the increase in AgNP cytotoxicity observed in BSO-treated cells is more modest than that observed for MCF-7 or MCF-10A cells. These results indicate that GSH levels can modulate the cytotoxicity of AgNPs, but neither the addition of exogenous GSH nor the inhibition of GSH synthesis had much effect on AgNP activity in the triple-negative MDA-MB-231 cells. This finding is of interest because increased GSH and GSH synthesis play a significant role in the resistance of breast cancer to chemoand radiation therapy. ${ }^{35,36}$

\section{Silver nanoparticles cause DNA damage and increase the effects of radiotherapy in TNBC cells to a greater extent than in non-TNBC and noncancerous breast cells}

AgNPs have been reported as radiation sensitizers for breast and other cancers, ${ }^{10,16-18}$ but despite significant differences in the underlying biology, the relative effect of AgNP-mediated radiosensitization on different breast cancer subtypes and nontumorigenic breast tissue has not been established. Therefore, we determined the sensitivity of MDA-MB-231 cells, MCF-7 cells, and MCF-10A cells to AgNP exposure alone or combined with IR. Initially, we quantified the phosphorylation of histone $2 \mathrm{AX}(\gamma \mathrm{H} 2 \mathrm{AX})$, an early biochemical process that occurs in the chromatin microenvironment surrounding a DNA double-strand break (Figure 6). Equal numbers of MDA-MB-231, MCF-7, and MCF-10A cells were exposed to AgNPs for 24 hours, then irradiated with a 4 Gy X-ray dose. DNA damage was quantified 1 hour following IR exposure by $\gamma \mathrm{H} 2 \mathrm{AX}$ ELISA. MDAMB-231 cells were extremely sensitive to exposure to both 10 and $25 \mu \mathrm{g} / \mathrm{mL}$ of AgNPs, and substantial $\gamma \mathrm{H} 2 \mathrm{AX}$ was detected. Additionally, at 1 hour postirradiation both doses of AgNPs significantly increased $\gamma \mathrm{H} 2 \mathrm{AX}$ in MDA-MB-231 cells compared to radiation alone. While $\gamma \mathrm{H} 2 \mathrm{AX}$ was found to increase in MCF-10A cells following AgNP exposure, AgNPs significantly increased $\gamma \mathrm{H} 2 \mathrm{AX}$ in these cells compared to radiation alone. An intermediate response was observed in MCF-7. $\gamma \mathrm{H} 2 \mathrm{AX}$ induced by AgNPs alone (at both doses) or in combination with IR was significantly greater in MDAMB-231s compared to MCF-10A cells $(P<0.05$ for $10 \mu \mathrm{g} / \mathrm{mL}$ AgNPs alone, and $P<0.01$ for 10 and $25 \mu \mathrm{g} / \mathrm{mL}$ doses of AgNPs combined with IR). $\gamma \mathrm{H} 2 \mathrm{AX}$ was also significantly greater in MDA-MB-231s compared to MCF-7 cells at the $25 \mu \mathrm{g} / \mathrm{mL}$ dose of AgNPs alone $(P<0.05)$ or at both the 10 and $25 \mu \mathrm{g} / \mathrm{mL}$ doses of AgNPs combined with IR $(P<0.01)$. These results indicate that AgNPs induced more DNA damage, with or without concurrent radiation treatment, in triple-negative MDA-MB-231 cells than in MCF-7 or MCF-10A cells.

Next, we determined the combined effects of AgNP exposure and IR on triple-negative MDA-MB-231 and BT-549 cells, MCF-7, and MCF-10A cells using the clonogenic assay. Cells were plated at low density ( 300 cells/well) and allowed 
A

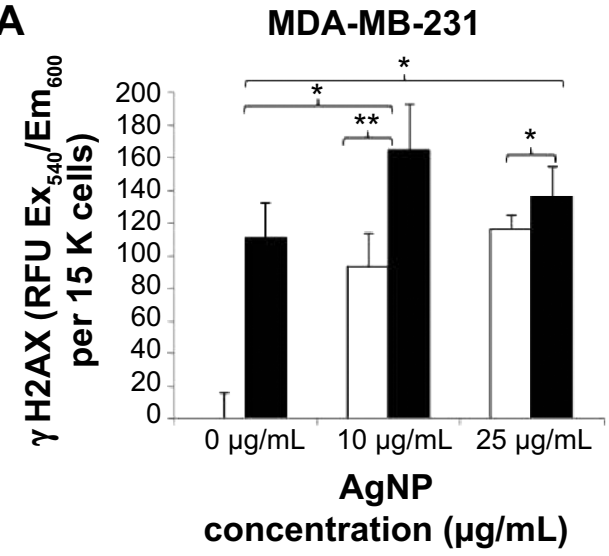

B

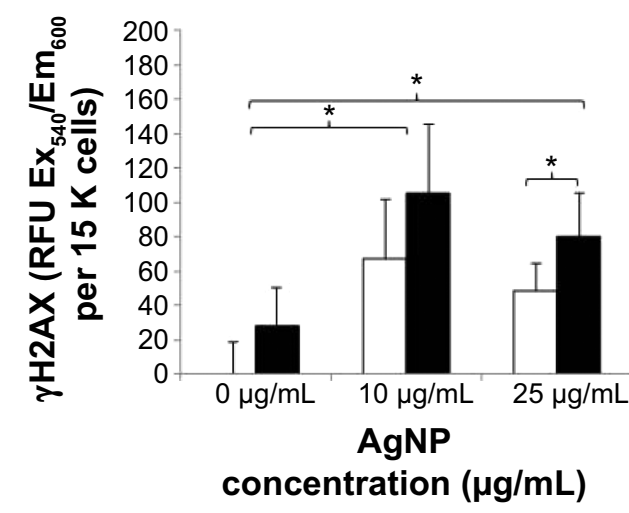

\section{C}

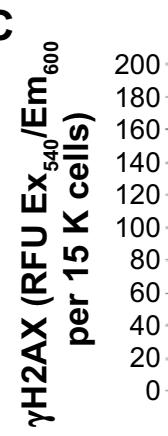

\section{MCF-10A}

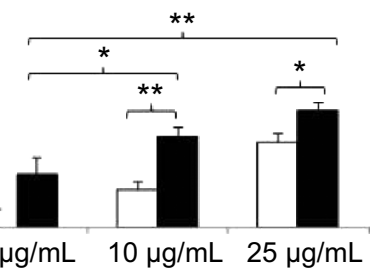

AgNP

concentration $(\mu \mathrm{g} / \mathrm{mL})$

Figure 6 Quantification of DNA damage induced by AgNPs alone or in combination with ionizing radiation.

Notes: Cells were incubated for 24 hours with $\operatorname{AgNP}(0,10$, or $25 \mu \mathrm{g} / \mathrm{mL})$, then exposed to ionizing radiation (4 Gy). To determine the effect of AgNPs and ionizing radiation on DNA damage, phosphorylation of histone $\mathrm{H} 2 \mathrm{AX}(\gamma \mathrm{H} 2 \mathrm{AX})$, which is indicative of DNA double-strand breaks, was quantified I hour after irradiation using an ELISA kit. (A) TNBC cells (MDA-MB-23Is), (B) luminal A breast cancer cells (MCF-7), and (C) non-tumorigenic breast cells (MCF-IOA). Data are presented as the mean of quadruplicate samples \pm SD. Background fluorescence from cells not exposed to AgNPs or ionizing radiation was subtracted from all measurements. Statistically significant differences in $\gamma \mathrm{H} 2 \mathrm{AX}$ levels in pairwise comparisons are indicated by $(* \mathrm{P}<0.05)$ or $(* * \mathrm{P}<0.0 \mathrm{I})$.

Abbreviations: AgNP, silver nanoparticle; ELISA, enzyme-linked immunosorbent assay; Em, emission; Ex, excitation; RFU, relative fluorescence units; TNBC, triple-negative breast cancer; SD, standard deviation.

to adhere overnight and then were treated with AgNPs. The following day, they were exposed to IR using an orthovoltage X-ray source. The data are presented as the surviving fraction of cells based on clonogenic growth normalized to the plating efficiency of cells exposed to the relevant dose of AgNPs in the absence of IR (Figure 7). Strikingly, an AgNP dose of as little as $1 \mu \mathrm{g} / \mathrm{mL}$ resulted in a dose enhancement of IR treatment (approximately 2-fold at the 2 Gy dose) for the TNBC cell lines (MDA-MB-231 and BT-549). Similar to the results shown in Figure 2, higher concentrations of AgNPs ( 5 and $10 \mu \mathrm{g} / \mathrm{mL}$ ) were extremely cytotoxic to the TNBC cell lines, and the addition of IR resulted in complete inhibition of clonogenic growth. MCF-7 cells were also sensitized to IR by AgNPs, but a 5 -fold greater AgNP dose $(5 \mu \mathrm{g} / \mathrm{mL})$ was required to achieve equivalent effects to those seen in TNBC cells. For MCF-10A cells, an even higher AgNP dose of $10 \mu \mathrm{g} / \mathrm{mL}$ was required before dose enhancing interactions with IR were observed. These results indicate that AgNPs can act as radiation dose enhancers for breast cancer in general, but are most effective at lower doses for the treatment of TNBC cells. Moreover, these data provide evidence that a substantial therapeutic window may exist for the use of AgNPs to enhance radiotherapy of TNBC in the absence of effects on nontumorigenic breast cells.

\section{Silver nanoparticles with or without ionizing radiation are effective for the treatment of TNBC xenografts in mice}

To assess the antitumor properties of AgNPs in vivo, xenografts of MDA-MB-231 breast cancer cells were grown in the flanks of nude mice. One group of mice received no treatment, thus serving as the control for the experiment. The second group received an intratumoral injection of AgNPs $\left(0.2 \mu \mathrm{g} / \mathrm{mm}^{3}\right.$ tumor volume). The third group 
A

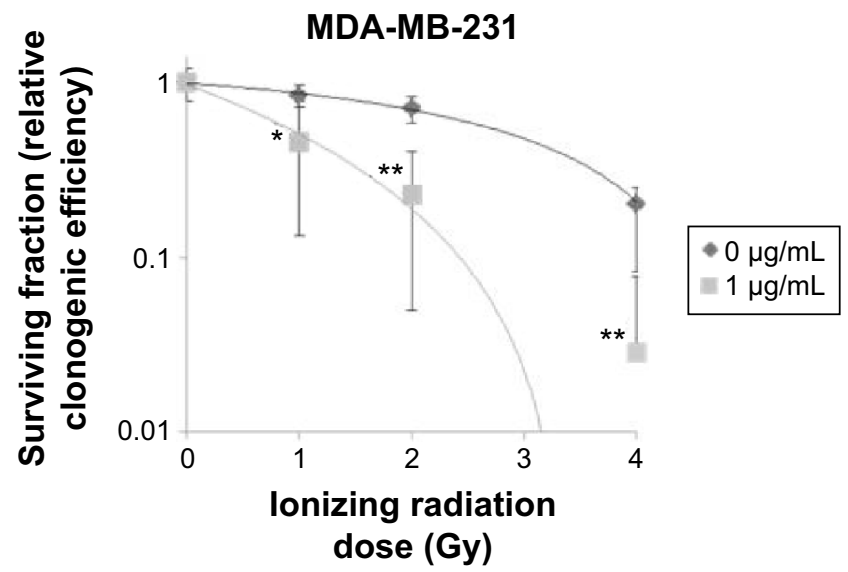

C

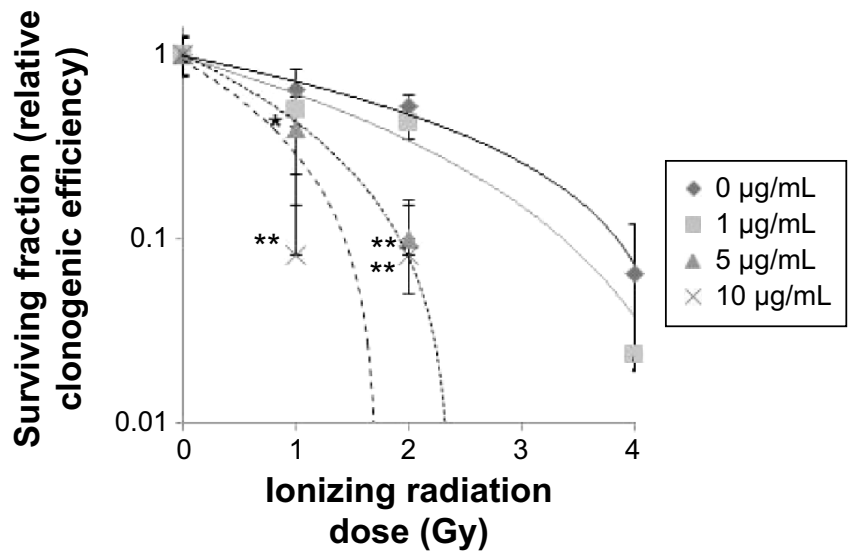

B

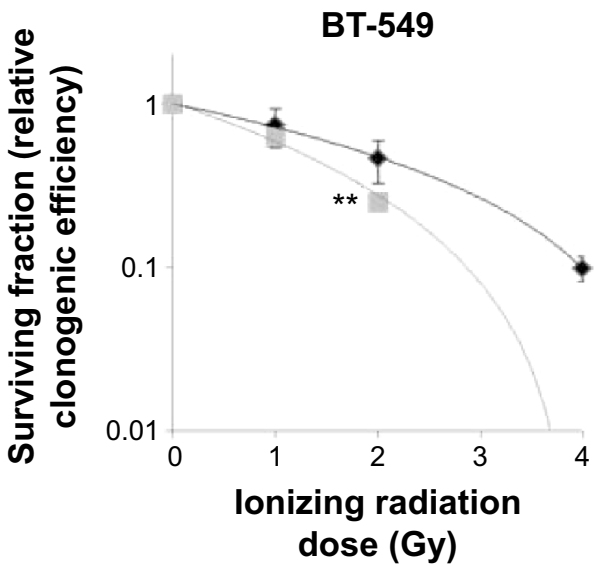

MCF-10A

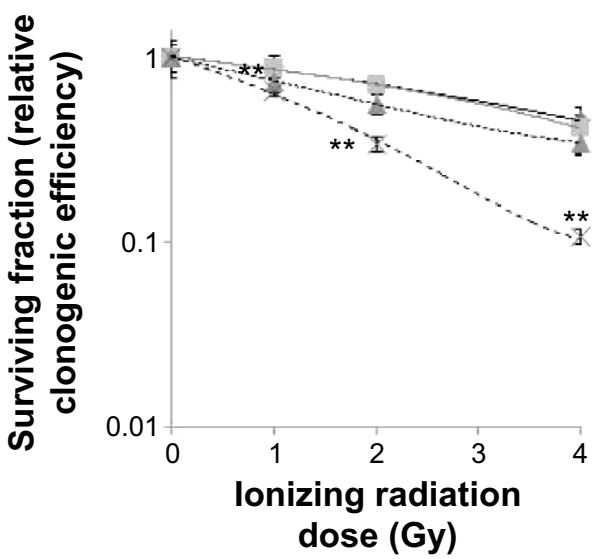

Figure 7 Quantification of cytotoxicity following treatment of cells with AgNPs and ionizing radiation.

Notes: MDA-MB-23I, MCF-7, and MCF-10A cells were allowed to adhere overnight (300 cells/well). The following day, fresh media containing increasing concentrations of AgNPs $(0-10 \mu \mathrm{g} / \mathrm{mL})$ were added. After overnight incubation, cells were thoroughly washed, then provided fresh media. Cells were then exposed to increasing doses of ionizing radiation (0-4 Gy). The combined effect of AgNP exposure and ionizing radiation was assessed via clonogenic assay I0-I4 days later: (A, B) TNBC cells (MDAMB-23I and BT-549), (C) luminal A breast cancer cells (MCF-7), and (D) nontumorigenic breast cells (MCF-IOA). Data are presented as the mean \pm SD of triplicate experiments and are normalized to cells treated with AgNPs in the absence of ionizing radiation. Data were found to best fit a second-order polynomial regression model. In (A), a single colony (from three wells) grew in the MDA-MB-23I cells treated with I $\mu \mathrm{g} / \mathrm{mL}$ of AgNPs and 4 Gy of ionizing radiation. This data point was a statistical outlier and was excluded from analysis for the purposes of curve fitting. Statistically significant differences in clonogenic growth in pairwise comparisons between cells exposed to ionizing irradiation alone or AgNPs plus ionizing radiation are indicated by $(* P<0.05)$ or $(* * P<0.01)$.

Abbreviations: AgNP, silver nanoparticle; TNBC, triple-negative breast cancer; SD, standard deviation.

received IR (4 Gy). The final group of mice received a combination therapeutic regimen of intratumoral AgNPs followed by IR. Three weeks later, each treatment was repeated. To minimize irradiation of other parts of the body, mice receiving radiation were shielded by lead excluding the tumor located on the flank. Treatment with AgNPs alone was equally effective as treatment with IR alone. The combination treatment of AgNPs and IR provided the greatest inhibition of tumor growth and resulted in a statistically significant decrease in tumor size as compared to untreated mice for all time points beyond day 26 ; however, there was no statistical difference between the AgNPs + IR, AgNP alone, and IR only treatment groups (Figure 8).

\section{Discussion}

With an ever increasing number of nanomaterials available to researchers to apply for potential oncology applications, the choice of which material to use for a specific type of cancer now is an important question. The ability to control the unique toxicity profiles of different nanomaterials will allow us to exploit specific vulnerabilities in cancer cells in a highly selective manner. ${ }^{20,21}$ In support of this concept, recent studies have shown that gold nanoparticles alone can inhibit ovarian tumor growth and metastasis in mice. ${ }^{21}$ Additionally, several groups showed that AgNPs have anti-breast cancer activity, ${ }^{5-7}$ but concerns over the safety profile of AgNPs have limited their clinical translation. Exposure to AgNPs is known to cause dose-dependent toxicities, including induction of 


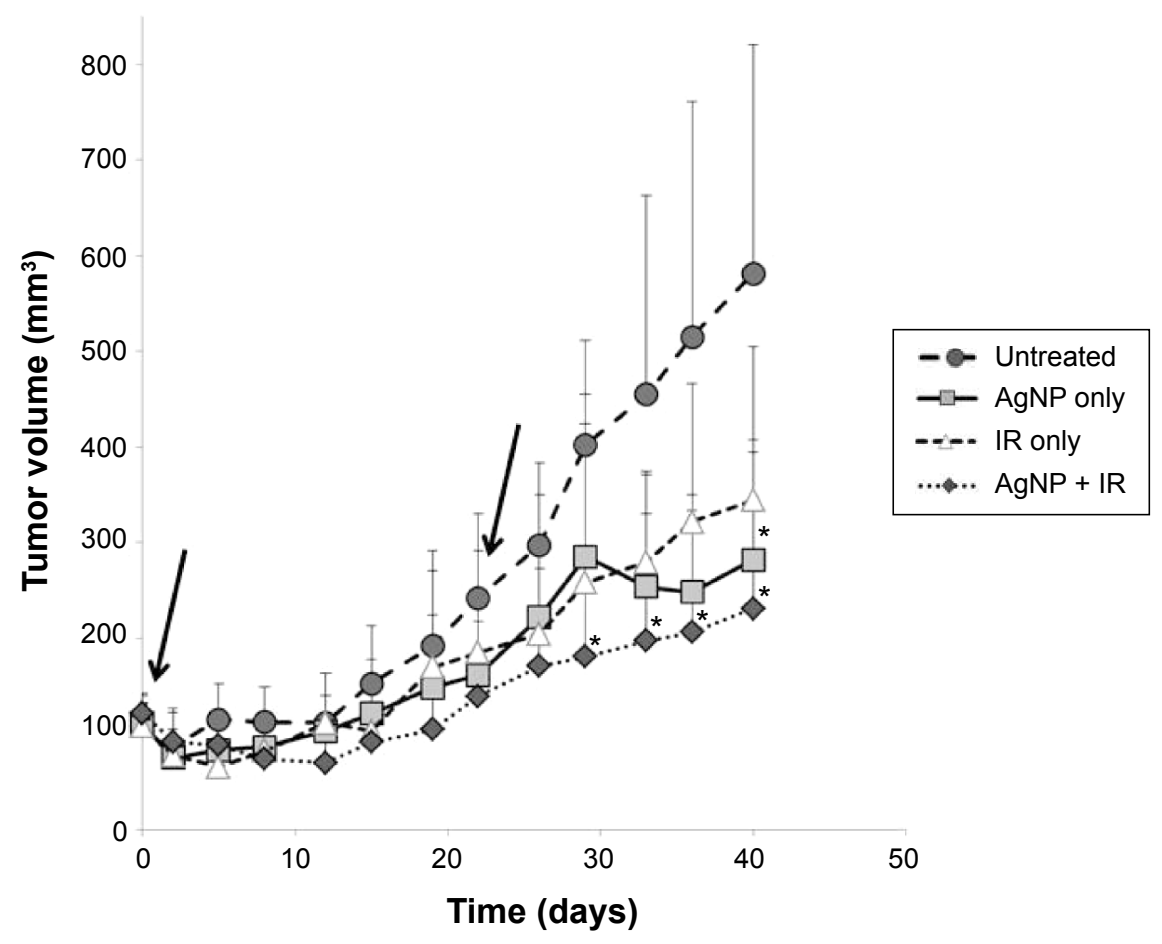

Figure 8 Treatment of TNBC xenografts in mice with AgNPs and ionizing radiation.

Notes: Nude mice were inoculated with MDA-MB-23I cells on the flank. Once tumors were established (approximately 100-120 mm ${ }^{3}$ ), they were left untreated or treated twice with AgNPs, IR, or AgNPs plus IR at the time points indicated with arrows. Tumors were measured biweekly and tumor volume was calculated. Statistically significant differences in tumor volume in pairwise comparisons between treated tumors and the untreated control are indicated by $(* P<0.05)$.

Abbreviations: AgNP, silver nanoparticle; TNBC, triple-negative breast cancer; IR, ionizing radiation.

oxidative stress and DNA damage, which can lead to cell death. ${ }^{14,22,23}$ Because TNBC subtypes are more vulnerable to agents that cause oxidative stress and DNA damage than other breast cancer subtypes ${ }^{30}$ we hypothesized that TNBC may be susceptible to AgNP cytotoxicity, a potential vulnerability that could be exploited for the development of new therapeutic agents. In agreement with this hypothesis, we observe that higher levels of protein-SOH and $\gamma \mathrm{H} 2 \mathrm{AX}$ are found in TNBC cells than in non-TNBC breast cancer cells or nontumorigenic breast cell lines following AgNP exposure. Furthermore, we find that AgNPs are cytotoxic to TNBC cells at doses that have little effect on noncancerous breast cells.

No prior studies have directly compared the cytotoxicity of any engineered nanomaterial between TNBC and noncancerous breast cells. In addition, few studies have directly compared the relative cytotoxicity of AgNPs on cancerous and noncancerous cell types, though recent reports indicate that AgNPs may be approximately 2-fold more cytotoxic toward acute myeloid leukemia as compared to normal bone marrow derived cells. ${ }^{15}$ For cytotoxic cancer therapy, identification of differential sensitivity of cancer cells as compared to normal tissue and cells has the potential to reveal a therapeutic window for safe use of AgNPs.
We have used multiple metrics including measurements of mitochondrial function (MTT assay), DNA replication (BrdU incorporation), and long-term proliferative potential (clonogenic assay) to demonstrate that AgNPs are highly cytotoxic toward TNBC cells at doses that have little effect on nontumorigenic breast cells or cells derived from liver, kidney, and monocyte lineages. This provides a clear rationale for further development of AgNP-based therapeutics for TNBC, which opens an important new direction for the biomedical use of AgNPs.

AgNPs have been reported to possess radiation doseenhancement effects. ${ }^{10,16-18}$ However, no previous studies have compared the relative dose-enhancement effects of AgNPs in cancerous and noncancerous cells, despite substantial differences in the underlying biology. Therefore, we assessed the effects of AgNPs on radiotherapy to determine if differences existed between TNBC, non-TNBC, and nontumorigenic breast cells. Our results illustrate that at low doses (less than $5 \mu \mathrm{g} / \mathrm{mL}$ ), AgNPs exhibit great cytotoxicity toward TNBC cells and work in combination with IR to kill TNBC cells in the absence of significant cytotoxicity or radiation dose enhancement in noncancerous breast cells. Moreover, intratumoral injection of AgNPs with or without radiation treatment 
can inhibit the growth of TNBC xenografts in mice. The potential morbidity of the treatment in mice was unknown, and therefore, a conservative treatment approach was selected. While these results are promising for future development of AgNPs as a therapeutic for TNBC, complete tumor regression was not seen for any of the treatment groups under the conditions tested. This may be due to a need to increase the AgNP dose to enhance the in vivo efficacy and to improve the distribution of the nanoparticles across the tumor volume. Additional fractionated doses of radiation may also result in increased therapeutic efficacy. More detailed studies will be needed to optimize treatment regimens. Ideally, systemically administered formulations of AgNPs specifically targeted to TNBC cells will be developed.

Promising results in mice already have been achieved with tumor-targeted gold nanoparticles used as radiation sensitizers for cancer therapy (reviewed by Lee et $\mathrm{al}^{46}$ ), and it remains to be determined if AgNPs can improve upon these results. However, studies using gold nanoparticles as radiation sensitizers for breast cancer ${ }^{47}$ have required higher doses of the nanoparticles and radiation (approximately $800 \mu \mathrm{g}$ gold nanoparticles and $11 \mathrm{~Gy}$ ) to achieve similar therapeutic efficacy to what we have achieved in vivo using approximately $20 \mu \mathrm{g}$ of AgNPs and a total dose of $8 \mathrm{~Gy}$ administered over two fractions. The low cytotoxicity and good biocompatibility profile of gold nanoparticles ${ }^{46}$ offer some advantages over AgNPs, but the selective cytotoxicity of AgNPs toward TBNC and the longer, safe clinical history of AgNP use are also significant considerations.

Biological thiols can interact with $\mathrm{AgNPs},{ }^{33}$ and GSH is the predominant form in which sulfur is stored in cells; therefore, we focused on the interaction of AgNPs with GSH, though it is likely that other forms of organosulfur interact with AgNPs. A previous report showed that cell lines exhibiting low GSH levels were more sensitive to AgNPs than those with a greater GSH content. ${ }^{48}$ In agreement with that study, we observe that selective depletion of GSH by BSO results in increased AgNP toxicity. Interestingly, modulation of GSH levels in triplenegative MDA-MB-231 cells has only a small effect on the cytotoxicity of AgNPs. This is quite striking when compared with the more dramatic influence of GSH modulation on AgNP cytotoxicity in MCF-7 and MCF-10A cells. However, in general, basal GSH levels are not clinically predictive of chemo- or radiation resistance in breast cancer and instead, it is the activity of enzymes involved in GSH synthesis, S-glutathionylation, and GSH recycling that are more significant indicators of poor therapeutic outcome. ${ }^{35,49}$ Thus, differences in GSH flux rather than steady state levels may play a role in the relative sensitivity of cell lines to AgNPs, but more research is needed to determine the precise mechanism involved.

The localization of AgNPs to vesicles (Figure 3) following the uptake by breast cells suggests that direct interactions between AgNPs and protein or nonprotein thiols may be limited. Using fluorogenic probes, multiple studies have shown that AgNPs increase the intracellular levels of ROS. ${ }^{14,15,22,23}$ While the levels of ROS are important for measuring generalized oxidative stress and to assess potential cytotoxic effects of nanomaterials, it is oxidative damage to biomolecules that leads to cell death. Assessment of protein-SOH provides quantitative information on potential oxidative damage at a critical point from which altered cell signaling, regulatory and toxic outcomes may arise. ${ }^{44}$ We note a dose-dependent increase in protein-SOH in $\mathrm{MCF}-7$ following exposure to AgNPs, but we observe far more protein-SOH in triplenegative MDA-MB-231 following exposure to AgNPs at $10 \mu \mathrm{g} / \mathrm{mL}$. However, lower levels of protein-SOH are detected in MDA-MB-231 cells treated with AgNPs at $25 \mu \mathrm{g} / \mathrm{mL}$ than the following treatment at $10 \mu \mathrm{g} / \mathrm{mL}$. This may be due to cell death, as a decrease in DNA replication and mitochondrial activity were seen at higher doses of AgNPs in TNBC cell lines. Protein-SOH following AgNP exposure is found at far lower levels in MCF-10A cells than in both the breast cancer cell lines that were tested, indicating that MCF-10A cells are able to tolerate AgNP-induced stress.

The toxicity of AgNPs is dependent on factors including particle size, shape, surface charge, and capping agent. ${ }^{50-53}$ The release of silver ions from AgNPs contributes to their cytotoxic potential, ${ }^{54}$ and it is believed that nanoparticle formulations of silver influence the rate, extent, location, and/or timing of silver ion release, ${ }^{55}$ which leads to different biological activity as compared to other forms of silver. Because significant dissolution of AgNPs can occur during storage in aqueous environments, we elected to use a powdered formulation of AgNPs and generated suspensions as needed. Our data indicate that dissolution during processing or storage of the AgNPs used for our studies does not appear to contribute to their cytotoxicity, and uptake of intact AgNPs was necessary for the observed cytotoxic effects. However, future development of AgNP-based therapeutics for TNBC will require more work to optimize specific physicochemical properties of AgNPs to increase the therapeutic window for selective treatment of TNBC and to develop systemically deliverable formulations. The detailed physicochemical analysis and dosing regimens of AgNPs, and the multiple viability and toxicity metrics presented in our work provide an important framework for these future studies. 


\section{Conclusion}

Breast cancer is the second leading cancer-related cause of death in women, ${ }^{56}$ and therefore, significant efforts are being made to develop new, nanotechnology-based therapeutic and diagnostic agents. ${ }^{1-3} \mathrm{~A}$ disproportionate number of breast cancer deaths are attributable to TNBC subtypes, ${ }^{57}$ and there remains significant room to develop more selective, less toxic alternatives to the current generation of therapeutics for TNBC. The PVP-capped AgNPs used in our study may represent such an alternative. AgNPs induced more DNA and oxidative damage in TNBC cells than in other breast cells, and they were significantly less cytotoxic to cells involved in the clearance of nanoparticles from the body (liver, kidney, and monocyte/macrophage) compared to TNBC cells. Enhanced cytotoxic effects due to the combination of $\mathrm{AgNPs}$ and IR were observed at low concentrations of AgNPs in TNBC cell lines without a comparable increase in cytotoxicity observed in noncancerous breast cells. Intratumoral injection of AgNPs reduced TNBC xenograft growth and improved radiation therapy in vivo. These studies show that AgNPs have the capacity to act as a single, self-therapeutic agent with a desirable combination of selective cytotoxicity and radiation dose-enhancement effects in TNBC at doses that that are nontoxic to noncancerous breast cells. When added with the possibility of developing AgNP-based imaging agents for cancer detection, ${ }^{19}$ these intrinsic properties of AgNPs and existing facile, scalable production capabilities make this an attractive agent for future development of a targeted therapeutic agent for TNBC.

\section{Acknowledgments}

We are grateful to Ken Grant, Paula Graham, and Brandi Bickford of the Wake Forest Comprehensive Cancer Center Cellular Imaging Shared Resource for assistance with microscopy, to Yelena Karpova of the Wake Forest Comprehensive Cancer Center Cell and Viral Vector Core Laboratory for assistance with cell lines, and to Brian Bernish for assistance with data collection and analysis. This work was supported in part by grant R00CA154006 (RS) from the National Institutes of Health, pilot funds from the Comprehensive Cancer Center of Wake Forest University supported by NCI CCSG P30CA012197, and by start-up funds from the Wake Forest School of Medicine Department of Cancer Biology. JS was supported in part by training grant T32CA079448 from the National Institutes of Health. JM was supported by the Wake Forest University Structural and Computational Biophysics training program (T32GM095440, predoctoral fellowship). We also acknowledge Nelmi O Devarie-Baez for synthesizing BP1 and the NCI/IMAT grant R33 CA1777461 for providing support for the development of BP1.

\section{Author contributions}

JS performed the research and wrote the manuscript; DLC provided conceptual advice and reviewed and edited the manuscript; SAA designed the research and reviewed and edited the manuscript; JM performed the research and wrote the manuscript; CMF designed the research and wrote the manuscript; SVT designed the research and wrote the manuscript; RNS designed and performed the research and wrote the manuscript.

\section{Disclosure}

The authors report no conflicts of interest in this work.

\section{References}

1. Heath JR, Davis ME. Nanotechnology and cancer. Annu Rev Med. 2008;59:251-265

2. Chow EKH, Ho D. Cancer nanomedicine: from drug delivery to imaging. Sci Transl Med. 2013;5(216):216rv4.

3. Bhattacharyya S, Kudgus RA, Bhattacharya R, Mukherjee P. Inorganic nanoparticles in cancer therapy. Pharm Res. 2011;28(2):237-259.

4. Chaloupka K, Malam Y, Seifalian AM. Nanosilver as a new generation of nanoproduct in biomedical applications. Trends Biotechnol. 2010; 28(11):580-588.

5. Gurunathan S, Han JW, Eppakayala V, Jeyaraj M, Kim JH. Cytotoxicity of biologically synthesized silver nanoparticles in MDA-MB-231 human breast cancer cells. Biomed Res Int. 2013;2013:535796.

6. Jeyaraj M, Sathishkumar G, Sivanandhan G, et al. Biogenic silver nanoparticles for cancer treatment: an experimental report. Colloids Surf B Biointerfaces. 2013;106:86-92.

7. Liu JH, Zhao YX, Guo QQ, et al. TAT-modified nanosilver for combating multidrug-resistant cancer. Biomaterials. 2012;33(26):6155-6161.

8. Locatelli E, Naddaka M, Uboldi C, et al. Targeted delivery of silver nanoparticles and alisertib: in vitro and in vivo synergistic effect against glioblastoma. Nanomedicine (Lond). 2014;9(6):839-849.

9. Sharma S, Chockalingam S, Sanpui P, Chattopadhyay A, Ghosh SS. Silver nanoparticles impregnated alginate-chitosan-blended nanocarrier induces apoptosis in human glioblastoma cells. Adv Healthc Mater. 2014;3(1):106-114.

10. Liu PD, Huang ZH, Chen ZW, et al. Silver nanoparticles: a novel radiation sensitizer for glioma? Nanoscale. 2013;5(23):11829-11836.

11. Miura N, Shinohara Y. Cytotoxic effect and apoptosis induction by silver nanoparticles in HeLa cells. Biochem Biophys Res Commun. 2009; 390(3):733-737.

12. Kawata K, Osawa M, Okabe S. In vitro toxicity of silver nanoparticles at noncytotoxic doses to HepG2 human hepatoma cells. Environ Sci Technol. 2009;43(15):6046-6051.

13. Beer C, Foldbjerg R, Hayashi Y, Sutherland DS, Autrup H. Toxicity of silver nanoparticles-Nanoparticle or silver ion? Toxicol Lett. 2012; 208(3):286-292.

14. Guo D, Zhao Y, Zhang Y, et al. The cellular uptake and cytotoxic effect of silver nanoparticles on chronic myeloid leukemia cells. J Biomed Nanotechnol. 2014;10(4):669-678.

15. Guo D, Zhu L, Huang Z, et al. Anti-leukemia activity of PVP-coated silver nanoparticles via generation of reactive oxygen species and release of silver ions. Biomaterials. 2013;34(32):7884-7894.

16. Xu R, Ma J, Sun X, et al. Ag nanoparticles sensitize IR-induced killing of cancer cells. Cell Res. 2009;19(8):1031-1034. 
17. Huang P, Yang DP, Zhang C, et al. Protein-directed one-pot synthesis of $\mathrm{Ag}$ microspheres with good biocompatibility and enhancement of radiation effects on gastric cancer cells. Nanoscale. 2011;3(9): 3623-3626.

18. Lu R, Yang D, Cui D, Wang Z, Guo L. Egg white-mediated green synthesis of silver nanoparticles with excellent biocompatibility and enhanced radiation effects on cancer cells. Int J Nanomedicine. 2012;7:2101-2107.

19. Braun GB, Friman T, Pang HB, et al. Etchable plasmonic nanoparticle probes to image and quantify cellular internalization. Nat Mater. 2014;13(9):904-911.

20. Soenen SJ, Demeester J, De Smedt SC, Braeckmans K. Turning a frown upside down: Exploiting nanoparticle toxicity for anticancer therapy. Nano Today. 2013;8(2):121-125.

21. Arvizo RR, Saha S, Wang EF, Robertson JD, Bhattacharya R, MukherjeeP. Inhibition of tumor growth and metastasis by a self-therapeutic nanoparticle. Proc Natl Acad Sci US A. 2013;110(17):6700-6705.

22. Hsin YH, Chen CF, Huang S, Shih TS, Lai PS, Chueh PJ. The apoptotic effect of nanosilver is mediated by a ROS- and JNK-dependent mechanism involving the mitochondrial pathway in NIH3T3 cells. Toxicol Lett. 2008;179(3):130-139.

23. Lim HK, Asharani PV, Hande MP. Enhanced genotoxicity of silver nanoparticles in DNA repair deficient Mammalian cells. Front Genet. 2012;3:104

24. Chen WY, Chang FR, Huang ZY, Chen JH, Wu YC, Wu CC. Tubocapsenolide A, a novel withanolide, inhibits proliferation and induces apoptosis in MDA-MB-231 cells by thiol oxidation of heat shock proteins. J Biol Chem. 2008;283(25):17184-17193.

25. Aykin-Burns N, Ahmad IM, Zhu Y, Oberley LW, Spitz DR. Increased levels of superoxide and $\mathrm{H}_{2} \mathrm{O}_{2}$ mediate the differential susceptibility of cancer cells versus normal cells to glucose deprivation. Biochem J. 2009;418:29-37.

26. Seo YH, Carroll KS. Profiling protein thiol oxidation in tumor cells using sulfenic acid-specific antibodies. Proc Natl Acad Sci U S A. 2009;106(38):16163-16168.

27. Pervin S, Tran AH, Zekavati S, Fulknto JM, Singh R, Chaudhuri G. Increased susceptibility of breast cancer cells to stress mediated inhibition of protein synthesis. Cancer Res. 2008;68(12):4862-4874.

28. Anderson WF, Rosenberg PS, Prat A, Perou CM, Sherman ME. How many etiological subtypes of breast cancer: two, three, four, or more? J Natl Cancer Inst. 2014;106(8):dju165.

29. Mayer IA, Abramson VG, Lehmann BD, Pietenpol JA. New strategies for triple-negative breast cancer - deciphering the heterogeneity. Clin Cancer Res. 2014;20(4):782-790.

30. Lehmann BD, Pietenpol JA. Identification and use of biomarkers in treatment strategies for triple-negative breast cancer subtypes. J Pathol. 2014;232(2):142-150.

31. Wu JH, Batist G. Glutathione and glutathione analogues; therapeutic potentials. Biochim Biophys Acta. 2013;1830(5):3350-3353.

32. Hamilton D, Batist G. Glutathione analogues in cancer treatment. Curr Oncol Rep. 2004;6(2):116-122.

33. Zhou YT, He WW, Lo YM, Hu XN, Wu XC, Yin JJ. Effect of silver nanomaterials on the activity of thiol-containing antioxidants. $J$ Agric Food Chem. 2013;61(32):7855-7862.

34. Hussain SM, Hess KL, Gearhart JM, Geiss KT, Schlager JJ. In vitro toxicity of nanoparticles in BRL 3A rat liver cells. Toxicol In Vitro. 2005; 19(7):975-983.

35. Diehn M, Cho RW, Lobo NA, et al. Association of reactive oxygen species levels and radioresistance in cancer stem cells. Nature. 2009;458(7239):780-783.

36. Gatti L, Zunino F. Overview of tumor cell chemoresistance mechanisms. Methods Mol Med. 2005;111:127-148.

37. Garbe JC, Bhattacharya S, Merchant B, et al. Molecular distinctions between stasis and telomere attrition senescence barriers shown by long-term culture of normal human mammary epithelial cells. Cancer Res. 2009;69(19):7557-7568.
38. MacCuspie RI, Allen AJ, Martin MN, Hackley VA. Just add water: reproducible singly dispersed silver nanoparticle suspensions ondemand. J Nanopart Res. 2013;15(7):1760.

39. Pinto VV, Ferreira MJ, Silva R, Santos HA, Silva F, Pereira CM. Long time effect on the stability of silver nanoparticles in aqueous medium: effect of the synthesis and storage conditions. Colloid Surf A. 2010;364(1-3):19-25.

40. de Lima R, Seabra AB, Duran N. Silver nanoparticles: a brief review of cytotoxicity and genotoxicity of chemically and biogenically synthesized nanoparticles. J Appl Toxicol. 2012;32(11):867-879.

41. Prat A, Karginova O, Parker JS, et al. Characterization of cell lines derived from breast cancers and normal mammary tissues for the study of the intrinsic molecular subtypes. Breast Cancer Res Treat. 2013;142(2):237-255.

42. Stampfer MR, Bodnar A, Garbe J, et al. Gradual phenotypic conversion associated with immortalization of cultured human mammary epithelial cells. Mol Biol Cell. 1997;8(12):2391-2405.

43. Hammond SL, Ham RG, Stampfer MR. Serum-free growth of human mammary epithelial cells: rapid clonal growth in defined medium and extended serial passage with pituitary extract. Proc Natl Acad Sci USA. 1984;81(17):5435-5439.

44. Furdui CM, Poole LB. Chemical approaches to detect and analyze protein sulfenic acids. Mass Spectrom Rev. 2014;33(2):126-146.

45. Qian J, Klomsiri C, Wright MW, et al. Simple synthesis of 1, 3-cyclopentanedione derived probes for labeling sulfenic acid proteins. Chem Commun (Camb). 2011;47(32):9203-9205.

46. Lee J, Chatterjee DK, Lee MH, Krishnan S. Gold nanoparticles in breast cancer treatment: Promise and potential pitfalls. Cancer Lett. 2014;347(1): 46-53.

47. Chattopadhyay N, Cai Z, Kwon YL, Lechtman E, Pignol JP, Reilly RM. Molecularly targeted gold nanoparticles enhance the radiation response of breast cancer cells and tumor xenografts to X-radiation. Breast Cancer Res Treat. 2013;137(1):81-91.

48. Mukherjee SG, O'Claonadh N, Casey A, Chambers G. Comparative in vitro cytotoxicity study of silver nanoparticle on two mammalian cell lines. Toxicol In Vitro. 2012;26(2):238-251.

49. Rotblat B, Grunewald TG, Leprivier G, Melino G, Knight RA. Anti-oxidative stress response genes: bioinformatic analysis of their expression and relevance in multiple cancers. Oncotarget. 2013; 4(12):2577-2590.

50. Verano-Braga T, Miethling-Graff R, Wojdyla K, et al. Insights into the cellular response triggered by silver nanoparticles using quantitative proteomics. ACS Nano. 2014;8(3):2161-2175.

51. Carlson C, Hussain SM, Schrand AM, et al. Unique cellular interaction of silver nanoparticles: size-dependent generation of reactive oxygen species. J Phys Chem B. 2008;112(43):13608-13619.

52. Ahamed M, Karns M, Goodson M, et al. DNA damage response to different surface chemistry of silver nanoparticles in mammalian cells. Toxicol Appl Pharm. 2008;233(3):404-410.

53. Lee KJ, Browning LM, Nallathamby PD, Xu XH. Study of ChargeDependent Transport and Toxicity of Peptide-Functionalized Silver Nanoparticles Using Zebrafish Embryos and Single Nanoparticle Plasmonic Spectroscopy. Chem Res Toxicol. 2013;26(6): 904-917.

54. Newton KM, Puppala HL, Kitchens CL, Colvin VL, Klaine SJ. Silver nanoparticle toxicity to Daphnia magna is a function of dissolved silver concentration. Environ Toxicol Chem. 2013;32(10):2356-2364.

55. Xiu ZM, Zhang QB, Puppala HL, Colvin VL, Alvarez PJ. Negligible Particle-Specific Antibacterial Activity of Silver Nanoparticles. Nano Lett. 2012;12(8):4271-4275.

56. Toriola AT, Colditz GA. Trends in breast cancer incidence and mortality in the United States: implications for prevention. Breast Cancer Res Treat. 2013;138(3):665-673.

57. Boyle P. Triple-negative breast cancer: epidemiological considerations and recommendations. Ann Oncol. 2012;23(Suppl 6):vi7-vi12. 


\section{Supplementary materials \\ Flow cytometry-based cell death assay}

Cells were grown to log phase in their respective media, trypsinized, washed in PBS, and plated on $10 \mathrm{~cm}$ plates at a density of $1.25 \times 10^{6}$ cells $/$ well for control plates and $3.0 \times 10^{6}$ cells/ well for AgNP treatment plates in $13 \mathrm{~mL}$ of complete media. Cells were treated with 0,10 , or $25 \mu \mathrm{g} / \mathrm{mL}$ AgNPs diluted in
$1 \times$ PBS for 24 hours. Both adherent and nonadherent cells were collected. Samples for flow cytometry-based cell death assay were prepared using the Fixation and Dead Cell Discrimination Kit (Miltenyi Biotec, Bergisch Gladbach, Germany), according to the manufacturer's instruction. Flow cytometry was performed using the Accuri ${ }^{\mathrm{TM}} \mathrm{C} 6$ Flow Cytometer, and data were analyzed using the FCS Express software.
A

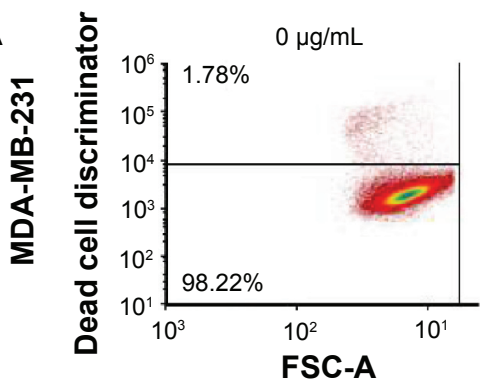

B

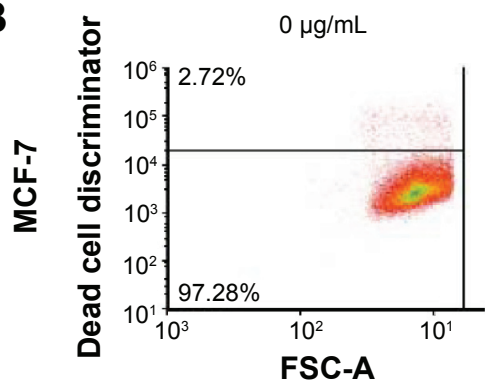

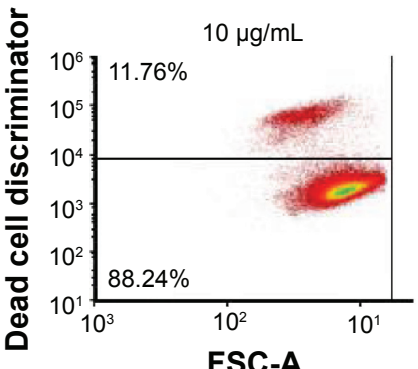

FSC-A

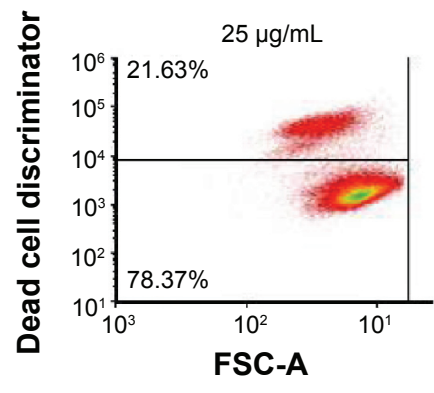

FSC-A
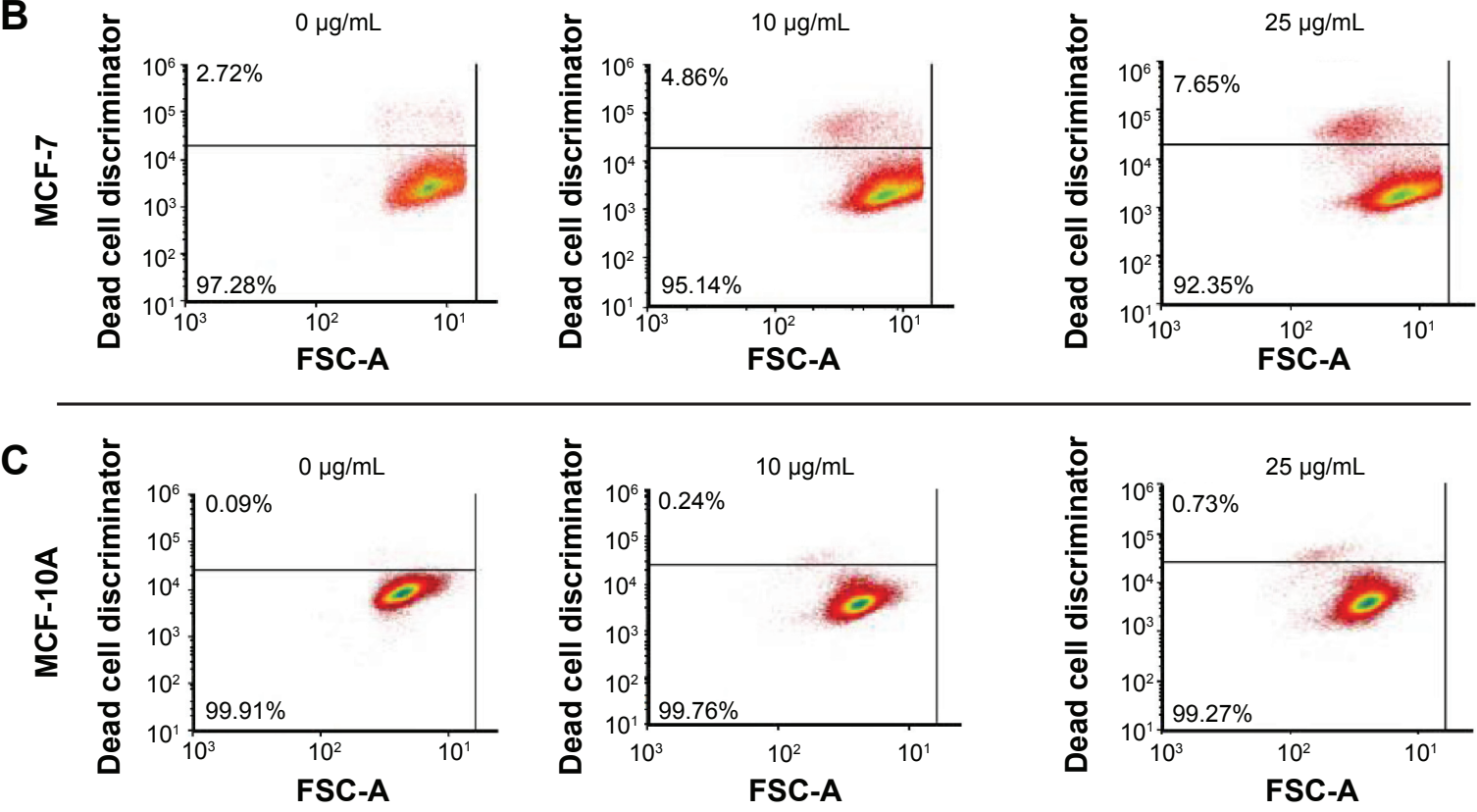

Figure SI Quantification of cell death following treatment with AgNPs.

Notes: A flow cytometry cell death assay based on exclusion of a fluorescent dye (dead cell discriminator) was used to determine the viability of cells after 24 hours of exposure to 0 , 10, or $25 \mu \mathrm{g} / \mathrm{mL}$ of AgNPs. Representative flow cytometry plots of dead cell discriminator fluorescence vs cell area (FSC-A) of singlet (A) MDA-MB-23I, (B) MCF-7, or (C) MCF-IOA cells exposed to AgNPs are shown. Increased staining with dead cell discriminator is indicative of a lack of membrane integrity and cell death. Cells above the indicated threshold in each graph were considered dead, while cells below the threshold were considered alive. The relative proportion of live or dead cells is shown as a percentage of total cells analyzed in each graph. At least 100,000 cells were included in each analysis.

Abbreviations: AgNP, silver nanoparticle; FSC-A, forward scatter.

International Journal of Nanomedicine

Dovepress

\section{Publish your work in this journal}

The International Journal of Nanomedicine is an international, peerreviewed journal focusing on the application of nanotechnology in diagnostics, therapeutics, and drug delivery systems throughou the biomedical field. This journal is indexed on PubMed Central, MedLine, CAS, SciSearch $®$, Current Contents ${ }^{\circledR} /$ Clinical Medicine,
Journal Citation Reports/Science Edition, EMBase, Scopus and the Elsevier Bibliographic databases. The manuscript management system is completely online and includes a very quick and fair peer-review system, which is all easy to use. Visit http://www.dovepress.com/ testimonials.php to read real quotes from published authors. 